\title{
Katholische Presse in den Niederlanden (II): Umstrukturierung und Meinungswandel nach dem Zweiten Weltkrieg ${ }^{1}$
}

von Joan Hemels

\section{Die Entwicklung der katholischen Tagespresse in der Nacbkriegszeit}

Im Herbst 1944 fragte man den Erzbischof von Utrecht, Msgr. Dr. J. de Jong, wie es um das Wiedererscheinen der überregionalen katholischen Tageszeitungen nach Kriegsende bestellt sein werde. Durch ein Publikationsverbot der deutschen Besatzung konnte "De Maasbode" bereits seit dem 4. Februar 1941 nicht mehr erscheinen; „Het Centrum" - das im Jahre 1932 den Anspruch einer überregional erscheinenden Tageszeitung endgültig aufgegeben hatte - ereilte ab 1. Oktober 1941 dasselbe Geschick, und am 4. Oktober 1941 stellte „De Volkskrant“, die bereits früher unter nationalsozialistischen Einfluß geraten war, ihr Erscheinen ein ${ }^{2}$. Auf Ersuchen des Episkopats setzte „De 'Tijd“, so recht und schlecht es ging, ihr Erscheinen mit einer Auflage von rund 75.000 Exemplaren fort. „De Tijd“ und „De Maasbode“ beabsichtigten nicht nur, nach der Befreiung ihre Vorkriegspositionen wieder einzunehmen, sondern ihre Eigentümer waren überdies auf Marktausweitung auf Kosten der Konkurrenz aus. "De Volkskrant" besaß einen noch weiter reichenden Ehrgeiz. Diese Zeitung hatte vor dem Krieg als Organ des „R. K. Werklieden-Verbond“ (Römisch-katholischer Arbeiterverband) gewiß nicht mit "De Tijd“ und „De Maasbode" konkurriert. Im Oktober 1909 hatten einige regionale Blätter der katholischen Arbeiterbewegung zum Wochenblatt „Het Katholieke Volk“ fusioniert, das seinerseits am 2. Oktober 1919 im Wochenblatt "De Volkskrant" aufgegangen war; am 1. Oktober 1921 Tageszeitung geworden, wurde „De Volkskrant" zunächst noch keine erfolgreiche Zeitung. Für die Eigentümerin, den „R. K. Werklieden-Verbond“, war jedoch bereits wichtig, daß man nunmehr über ein Organ verfügte, in dem man seine Kommuniqués veröffentlichen konnte ${ }^{3}$. $\mathrm{Zu}$ jenen, die den Erzbischof mit Fragen über das katholische Pressewesen nach der Befreiung angingen, gehörte auch der Bischof von Haarlem, Msgr. J. P. Huibers. In einem Brief vom 8. September 1944 fragte der Haarlemer Bischof Msgr. De Jong nach dem Wiedererscheinen von „De Maasbode“, den er als „brotnotwendig“ erachtete. Ehe er antwortete, holte der Erzbischof sich Rat bei Msgr. J. G. van Schaik, dem geistlichen Berater des R. K. Werklieden-Verbond vor dem Krieg. Dieser ließ Msgr. De Jong wissen, er erachte es als notwendig, daß "De Maasbode" und "De Volkskrant" und - in Klammern geschrieben - "womöglich auch ,De Tijd“" — unmittelbar nach dem Krieg wieder erschienen. "De Volkskrant" sollte bereits Maßnahmen für das Wiedererscheinen treffen und sich bereithalten, mit "De Maasbode" zusammen ein Gebäude zu beziehen, und zwar womöglich in Amsterdam. Aufgrund dieses Rates von Msgr. Van Schaik - der noch öfter in Sachen der katholischen Presse Rat erteilen sollte schrieb der Erzbischof seinem Amtsbruder in Haarlem, er habe keine Einwände gegen das Wiedererscheinen von "De Maasbode“. Noch im selben Monat Dezember

Dr. Joans Hemels ist wissenschaftlicher Mitarbeiter am Institut für Massenkommunikation der Katholischen Universität Nimwegen (Niederlande). Seit 1968 war er Korrespondent und freier Mitarbeiter von „De Tijd“. 
1944 ließ L. G. A. Schlichting Msgr. De Jong in einem Brief wissen, daß „De Tijd“ nach dem Krieg so bald wie möglich wieder täglich erscheinen solle. Infolge Papiermangels erschien "De Tijd" seit Anfang 1944 nur noch zweimal wöchentlich in einer Auflage von etwa 75.000 Exemplaren. Übrigens wurde Schlichting im Mai 1943 der Status Journalist von den Besatzern abgesprochen, so daß er auch kein Chefredakteur mehr sein konnte. Er blieb in ständigem Kontakt mit der Eigentümerin von „De Tijd“ (NV De Spaarnestad) und dem Episkopat.

Wir haben die vorgenannten Einzelheiten an dieser Stelle eingefügt, weil daraus zu ersehen ist, daß die überregionalen katholischen Tageszeitungen ihre Vorkriegsposition wieder einnehmen wollten und daß sie dafür tatsächlich bereits im September 1944 - auch vom Episkopat - grünes Licht erhielten. Warum das einiges Befremden hervorrufen mag, zeigt sich aus dem, was sich zuvor abgespielt hat ${ }^{4}$.

Bereits in den Jahren 1942 und 1943 nahm J. Asberg frühzeitig zusammen mit C. P. M. Romme Kontakt auf zu Msgr. De Jong, um über eine Neuorganisation der katholischen Presse nach dem Zweiten Weltkrieg zu sprechen. Asberg war ein erfolgreicher Verleger, der sich jedoch vor dem Krieg um die Herausgabe von Tageszeitungen nicht gekümmert hatte. Romme war ein verhältnismäßig junger katholischer Politiker der „R. K. Staatspartij“ (Römisch-Katholische Staatspartei) aus der Vorkriegszeit und war von 1937 bis 1939 Sozialminister gewesen. Nach vorbereitenden Besprechungen im Herbst 1943 mit Romme und Asberg richtete Erzbischof De Jong am 3. Februar 1944 die „Commissie van Bisschoppelijke Adviseurs inzake Persplan“ (Kommission Bischöflicher Berater für den Presseplan) ein, meistens kurz bezeichnet als die Kommission Romme-Asberg, womit die Initiatoren schon genannt waren. Der Auftrag des Episkopats an die Kommission läßt sich wie folgt zusammenfassen: Die Bischöfe verlangten über die Möglichkeit einer neuen Struktur im katholischen Pressewesen informiert zu werden, das heißt einer Struktur, die a) im katholischen Volksteil wurzele, b) durch eine katholische Pressestiftung vertreten werde und c) mit iden angemessenen Ansprüchen der erprobten Verdienste und Interessen auf dem Gebiet der katholischen Presse vereinbar sei ${ }^{5}$. Msgr. De Jong hatte, wie er selbst mitteilte, von Romme und Asberg einen Plan für eine "Katholieke Pers Stichting “ (KPS = Katholische Pressestiftung) erhalten; dieser Plan sollte als Leitlinie für die Besprechungen dienen. Obgleich innerhalb der KPS selbständige Abteilungen für die überregionalen und regionalen katholischen Tageszeitungen Raum finden sollten, begrenzten sich die Besprechungen doch rasch auf die überregionalen Tageszeitungen „De Tijd“, „De Maasbode“ und „De Volkskrant". Die Zusammenstellung der Kommission spielte dieser Eingrenzung bereits in die Hand. Grundgedanke des Presseplans war, daß die katholische Presse nach dem Krieg auf einer "gemeinschaftlichen Grundlage“ aufgebaut werden sollte. Hierunter verstand man einen Aufbau von Eigentum und Verwaltung einer oder mehrerer Tageszeitungen (und eventuell auch Wochenblättern und anderen Blättern) derart, daß Eigentum und Leitung nicht in Händen einer bestimmten kommerziellen Interessengruppe liegen könnten. Der Presseplan lehnte deshalb die sogenannte „private Grundlage", wir würden heute sagen: die privatwirtschaftlich-unternehmerische Herstellung für Tageszeitungen und dergleichen ab. Nicht private, auf Gewinn ausgerichtete Unternehmen, sondern die katholische Gemeinschaft, die Offentlichkeit des gemeinsamen katholischen Lebens in den Niederlanden sollte Träger der katholischen Presse sein. Abgesehen von Einzelheiten kann man daraus schließen, daß der Presseplan seiner ursprünglichen Anlage nach auf ein überregionales katholisches "Großblatt" vom 
Charakter eines journal d'opinion und ein überregionales katholisches „Volksblatt" vom Charakter eines journal d'information abzielte. Nach ausgiebiger Diskussion definierte die Kommission den Begriff "Großblatt" als: ein großes überregionales Hauptorgan mit Morgen- und Abendausgabe, allgemeinhin bestimmt für die finanziell tragfähigeren beziehungsweise intellektuell entwickelteren Bevölkerungsgruppen. „De Maasbode“, wie er vor dem Krieg gewesen war, stand dafür Modell. Unter „Volksblatt“ verstand man somit also eine überregionale Tageszeitung, speziell bestimmt für die mit Geld und Bildung minder bemittelten Bevölkerungsgruppen, in Berichterstattung und Kommentaren auf dieses Leserpublikum spezialisiert. Die Initiatoren des Presseplans sahen es als möglich an, das Volksblatt gegebenenfalls nur morgens und das Großblatt nur abends erscheinen zu lassen, so daß die technische Ausrüstung für die Herstellung und der administrativ-technische Apparat für den Vertrieb beider Zeitungen optimal genutzt werden könnten.

Zwischen dem 3. Februar und dem 29. August 1944 fanden acht Versammlungen statt und wurden umfangreiche Dossiers erarbeitet. Die Tätigkeit wurde unterbrochen, offiziell weil man im Herbst, Winter und Frühjahr 1944/1945 durch die schlechten Verkehrsverbindungen des letzten Kriegshalbjahres am Treffen gehindert wurde. Unseres Erachtens gibt es jedoch auch Anzeichen dafür, daß die Besprechungen sich am Unwillen von zumindest einem Teil der Gesprächspartner festgefahren hatten. Msgr. De Jong, der vom einen und vom anderen wußte, beantwortete den Brief des Haarlemer Bischofs über das Wiedererscheinen von "De Maasbode" denn auch im September 1944, ohne um Aufschub zu bitten, allerdings auch ohne auf die Besprechungen der Kommission Romme-Asberg hinzuweisen.

So wie der in diesem Punkt gut informierte Van Schaik Erzbischof De Jong bereits im September 1944 zu verstehen gab, wollte die katholische Arbeiterbewegung "De Volkskrant $^{\text {" }}$ nach dem Krieg in Amsterdam und nicht mehr in Utrecht erscheinen lassen. Amsterdan, die journalistische Hochburg der Niederlande, böte einen besseren Nährboden für eine auf Nachrichten ausgerichtete Zeitung und würde zudem die Beziehung mit der in Utrecht sitzenden Gewerkschaft lockern. An erster Stelle sollte "De Volkskrant" eine gute Zeitung und erst dann eine katholische Zeitung sein. Der neu zu ernennende allgemeine Chefredakteur (es wurde J. M. Lücker) dürfe auch nicht aus dem Kreis der katholischen Arbeiterbewegung kommen. Die politische Linie müsse bestimmt werden durch einen auch in der Nachkriegs-Journalistik der Niederlande noch nicht aus der Mode gekommenen politischen Chefredakteur; das wurde Romme, der zugleich Fraktionsführer der „Katholieke Volkspartij“ (KVP) in der Zweiten Kammer werden sollte. Im Winter und Frühjahr 1944/1945 wurde an der Vorbereitung zum Wiedererscheinen von "De Volkskrant" in Amsterdam hart gearbeitet. Der Bischof von Haarlem und die NV De Spaarnestad als Eigentümerin von „De Tijd“ befürchteten, daß sowohl die Volksausgabe von „De Tijd“, „De Nieuwe Dag“ genannt, als auch „De Tijd“ selbst ernsthafte Konkurrenz in "De Volkskrant" erhalten würden. Mitte Februar 1945 stellte auch Erzbischof De Jong die Frage, ob nach dem Krieg wohl noch Platz sei für eine Volkstageszeitung wie "De Volkskrant" neben „De Tijd“, „De Maasbode" und den regionalen katholischen Tageszeitungen, die auch wieder in großer Zahl erscheinen würden. Er deutete an, daß er dabei nicht an den kommerziellen Erfolg oder Fehlschlag einer solchen Zeitung denke, sondern an die Frage nach der Bedeutung einer Volkstageszeitung für die katholische Gemeinschaft. Würde die Bedeutung für die katholische Sache nicht klar auf der Hand liegen, dann könne der Episkopat ihre Gründung zwar nicht verhindern, aber ihr Wachstum doch wohl zügeln. Als Mittel dazu dachte Msgr. De Jong 
daran, einen bischöflichen Zensor und damit der Zeitung das Prädikat „katholisch“ zu verweigern und den Geistlichen aufzutragen, den Gläubigen von einer solchen nichtkatholischen [sic] Zeitung abzuraten. Daß „De Volkskrant “ doch einen Zensor bekam, verdankt sie unseres Wissens vornehmlich dem Einfluß, den Msgr. Van Schaik beim Erzbischof hatte. Obgleich man erst daran gedacht hatte, diesen Untertitel wegzulassen, erschien "De Volkskrant" dann am 8. Mai 1945 in Amsterdam

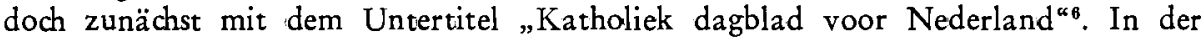
ersten Ausgabe wurde bereits deutlich abgezielt auf eine zweite Lesergruppe, die "De Volkskrant" vor dem Krieg nicht hatte erreichen wollen: die Mittelschicht. "Nach beinahe vier Jahren aufgezwungenen Schweigens" - so die redaktionelle Eröffnungserklärung - „steht ,De Volkskrant' wieder auf. Verjüngt, mit neuer Geisteskraft und bereit, als katholische Tageszeitung für unser ganzes Volk Arbeiter und Mittelständler - Ideen und Ideale hinauszutragen."

Am 7. Mai 1945 erschien die erste Nachkriegsausgabe von „De Maasbode“; „Het Nieuwe Dagblad", die Volksausgabe von "De Tijd“, erschien nach gut vier Jahren zum ersten Mal wieder am 28. Juli 1945; "De Tijd“ selbst mußte nach der Befreiung das Untersuchungsergebnis hinsichtlich ihrer Haltung während der Kriegsjahre abwarten und ihr Erscheinen vorerst unterbrechen, bekam aber am 14. Juni 1945 bereits die Nachricht, daß sie wieder als Tageszeitung erscheinen könne. Die Tabelle 1 zeigt, wie die Auflagenziffern der überregionalen katholischen Tageszeitungen sich nach dem Krieg entwickelten.

Tabelle 1: Auflagenverteilung der überregionalen katholischen Tageszeitungen in den Niederlanden von 1947 bis 1974:

\begin{tabular}{|c|c|c|c|}
\hline & „De Volkskrant ${ }^{c}$ & „De Tijd“ & „De Maasbode“ \\
\hline 1947 & 151.132 & 70.883 & 61.225 \\
\hline 1948 & 171.135 & 75.826 & 60.205 \\
\hline 1949 & 168.933 & 77.484 & 58.939 \\
\hline 1950 & 162.145 & 75.048 & 56.590 \\
\hline 1955 & 147.324 & 67.658 & 52.040 \\
\hline 1958 & 156.126 & 68.958 & 48.357 \\
\hline 1959 & 158.286 & & \\
\hline 1960 & 164.800 & \multicolumn{2}{|c|}{113.981} \\
\hline 1965 & 164.900 & \multicolumn{2}{|c|}{121.134} \\
\hline 1966 & 171.100 & \multicolumn{2}{|c|}{106.485} \\
\hline 1967 & 179.100 & \multicolumn{2}{|c|}{100.847} \\
\hline 1968 & 184.600 & \multicolumn{2}{|c|}{95.349} \\
\hline $1969^{*}$ & 185.500 & \multicolumn{2}{|c|}{95.062} \\
\hline 1970 & 192.800 & \multicolumn{2}{|c|}{94.218} \\
\hline 1971 & 201.100 & \multicolumn{2}{|c|}{93.182} \\
\hline 1972 & 201.400 & \multicolumn{2}{|c|}{100.558} \\
\hline 1973 & 200.300 & \multicolumn{2}{|c|}{75.013} \\
\hline 1974 & 206.400 & \multicolumn{2}{|c|}{64.791} \\
\hline
\end{tabular}

Quelle: J. Hemels: Manuskript (mit Angaben der verschiedenen Quellen).

* Von 1969 ab geben wir die im Schnitt verkaufte Auflage im ersten Jahresviertel an. Die Zahlen von 1947 bis 1968 sind Augenblicksbestandsaufnahmen vom letzten September. 
Als das Wiedererscheinen der drei genannten überregionalen katholischen Tageszeitungen bereits einige Monate Tatsache war, bemühte sich der Episkopat immer noch, eine Zusammenarbeit zustande zu bringen. Ausgangspunkt bildeten der vom Vorsitzenden Romme namens der Kommission Romme-Asberg herausgegebene Zwischenbericht vom 19. März 1945. Die genannte Kommission erhielt einen Sekretär in der Person von J. H. Wreesman und trat vom 16. bis 17. November 1945 erstmals wieder zusammen. Der im Februar 1947 herausgegebene Schlußbericht lieferte jedoch keine Anhaltspunkte für die beabsichtigte Zusammenarbeit. Im Herbst 1948 sprach Jan Derks, der Chefredakteur von "De Tijd“, mit dem inzwischen Kardinal gewordenen Erzbischof De Jong über einen neuen Versuch, die überregionalen katholischen Tageszeitungen zur Zusammenarbeit zu bewegen. Am 1. Dezember desselben Jahres noch ersuchte der Kardinal Dr. J. de Quay, den Kommissar der Königin in der Provinz Nord-Brabant, unparteilich den Vorsitz einer zwischen den Direktionen von „De Tijd", „De Volkskrant" und „De Maasbode" zu bildenden Kommission zu übernehmen. Alle Tageszeitungen hatten nach dem Krieg mit enormer Steigerung von Herstellungs- und Vertriebskosten zu kämpfen. Zusammenarbeit wurde überdies als dringender denn je erachtet, weil die zu erwartende weitere Zuweisung des sehr wichtigen, aber knappen Rohstoffs Papier von Staats wegen die Konkurrenz mit den nichtkatholischen Tageszeitungen noch schwieriger gestalten würde. Während der stockend verlaufenden Verhandlungen machte nun gerade ${ }_{\text {"De Maasbode }}$ Schwierigkeiten: die Zeitung fürchtete, daß im Fall einer Fusion Amsterdam als Erscheinungsort gewählt würde. Nach außen hin würde dies den Eindruck erwecken, „De Maasbode“ hätte kapitulieren müssen. Überdies hoffte dieses Rotterdamsche Organ auch, daß NV De Spaarnestad nicht innerhalb von Tagen bereit sein werde, die Fehlbeträge von "De Tijd“ auszugleichen. „De Volkskrant" gab sich verbindlich, fand aber doch, daß „De Maasbode“ und „De Tijd“ erst zusammenfinden müßten. Nach ihrer Auffassung wäre Platz für ein MeinungsAbendblatt mit dem Charakter der genannten Tageszeitungen und ein NachrichtenMorgenblatt, nämlich „De Volkskrant" gewesen. Die am 8. Februar 1949 begonnenen Gespräche wurden am 13. Dezember 1951 beendet. Am 4. Februar 1952 wurde der Erzbischof vom Fehlschlagen dieser zweiten Bemühung um die Neuorganisation der überregionalen katholischen Tagespresse unterrichtet. Am 5. September desselben Jahres bezog "De Maasbode" ein neues Gebäude, und die neue Druckmaschine wurde nach dem Brauch der Zeit eingesegnet. In einer Nachschrift der Redaktion (von Jan Derks?) zu einem Leserbrief hatte "De Tijd“ am 9. Juni 1951 bereits geschrieben: "... hinreichende Mittel (für das ,Katholiek Nederlands Persbureau' $=$ KNP) werden erst zu finden sein, wenn das Problem der katholischen Presse in den Niederlanden, dem Bereich des privaten Unternehmensinteresses enthoben, als Gemeinschaftsinteresse, als Anliegen nämlich der Gemeinschaft der niederländischen Katholiken und als solches der gesamten niederländischen Gemeinschaft untersucht und verwirklicht wird."

\section{Die Wiedererrichtung der katholischen Presseorganisationen auf Wunsch des Episkopats}

Die erste katholische Organisation im Pressebereich, die nach dem Krieg wieder errichtet wurde, war die Vereinigung der Direktoren katholischer Tageszeitungen, die "Katholieke Nederlandsche Dagbladpers" (KNDP = Katholische Niederländische Tagespresse); das geschah am 20. Dezember 1945. In Artikel 6, Absatz 2, der Statuten 
der KNDP fand sich folgende Umschreibung einer katholischen Tageszeitung: eine mindestens sechsmal wöchentlich erscheinende Zeitung, der durch die zuständige kirchliche Obrigkeit ein Zensor zugewiesen ist. Im Hinblick auf die zu erwartenden gesetzlichen Regelungen im Bereich der Presse - wohl oder übel auf eine korporatistische öffentlich-rechtliche Ordnung des Pressewesens hinauslaufend - und aufgrund des in den Kriegsjahren entstandenen Begriffs von der Notwendigkeit, weltanschauliche Grenzen zu überschreiten (der sogenannte "Durchbruchsgedanke"), regte sich bei einer Anzahl katholischer Journalisten der Wunsch, eine Organisation für alle Journalisten zu gründen. Im Dezember 1945 trafen sich einige katholische Journalisten, um diese Frage zu besprechen. Eine zahlenmäßig nicht festzulegende Anzahl katholischer Journalisten und der Episkopat wünschten jedoch eine eigene Organisation. Am 20. April 1946 teilte Kardinal De Jong schriftlich mit, daß er auch nichts von der Bildung einer allgemeinen Vereinigung von Journalisten zur Wahrnehmung sozial-ökonomischer Belange aller Journalisten neben einer besonderen Organisation zur Wahrnehmung der spezifisch katholischen und kulturellen Belange hielt. Eine "föderative Zusammenarbeit in den Spitzenorganen" der verschiedenen privatrechtlichen Journalistenorganisationen erachtete er jedoch als durchaus wünschenswert. Dadurch würde in der Wahrnehmung der sozial-ökonomischen Belange praktisch eine Einheit zustande kommen können, besonders bei der Vertretung von Belangen nach außen hin. So wurde am 27. April 1946 der neutrale „Nederlandse JournalistenKring" (NJK = Niederländischer Journalistenkreis) neu ins Leben gerufen, fand am 13. Mai 1946 die Stiftungsversammlung des „Katholieke Nederlandse Journalisten-Kring" (KNJK = Katholischer Niederländischer Journalistenkreis) statt und wurde am 23. November desselben Jahres die „Federatie van Nederlandse Journalisten" (FNJ = Bund Niederländischer Journalisten) gegründet. In diesem Bund schlossen sich der „NJK" und der "KNJK" zusammen; 1948 wurde auch die „Protestants-Christelijke Journalisten-Vereniging " (Protestantisch-Christliche Journalistenvereinigung) unter dem Namen „Protestants-Christelijke Journalisten-Kring“ (PCJK = Protestantisch-Christlicher Journalistenkreis) in den Bund aufgenommen.

$\mathrm{Zu}$ den Organisationen der katholischen Presse gehört auch das „Katholiek Nederlands Persbureau" (KNP), das im Oktober 1946 durch die Initiative der KNDP und der "Katholieke Actie in Nederland" (Katholische Aktion in den Niederlanden) als Stiftung ins Leben trat. Der Chefredakteur des KNP, H. B. A. M. Kemna, wurde am 23. November 1949 von Papst Pius XII. und dessen Substitut im Staatssekretariat, Msgr. G. B. Montini, dem heutigen Papst Paul VI., empfangen. Aus Anlaß des Empfangs überreichte der Papst einen Beitrag von dreißigtausend Gulden für den Ausbau von KNP.

Auf Anregung des Vorstandes der KNDP fanden im Jahre 1947 Besprechungen statt, die zur Einrichtung einer "Commissie van Samenwerking voor de Katholieke Pers" (Kommission zur Zusammenarbeit für die Katholische Presse) führten. An der Beratung nahmen die KNDP, der KNJK und die katholischen Verleger von Nachrichtenblättern, Zeitschriften und die Meinungswochenblätter „De Linie“, „De Nieuwe Eeuw" und "Het Kompas" teil. Im August 1948 billigte der Episkopat den Vorschlag, eine übergreifende Stiftung für sämtliche katholischen Organisationen im Pressebereich zu bilden. Um den Kontakt mit dem Episkopat und die Kontrolle von seiner Seite aus zu verbessern, wurde vom 1. November 1948 an ein ,aalmoezenier van de Pers" (Pressegeistlicher) zur Vertretung der verschiedenen geistlichen Berater ernannt. Der Pressegeistliche war außerdem Zensor des KNP und der katholischen regionalen Tageszeitung "Het Binnenhof", die beide ihren Sitz in 
's-Gravenhage hatten. In einem offenen Brief vom 9. März 1949 an den neu ernannten Pressegeistlichen, Pater Dr. P. Heymeijer S. J., äußerte der Episkopat unter anderem den nicht mißzuverstehenden Wunsch, daß auch die katholischen Verleger von Nachrichtenblättern und die der Meinungswochenblätter eigene Organisationen errichten sollten ${ }^{8}$. Ferner schrieben die Bischöfe, sie erachteten es als sehr erwünscht, daß der bereits angekündigte „Stichting Raad voor de Katholieke Pers“ (Stiftungsrat für die Katholische Presse) zustandekäme. Dem Bischofswunsch wurde sogleich entsprodhen: noch im Frühjahr rief die "Commissie van Samenwerlsing voor de Katholieke Pers" die "Stichting Katholieke Nederlandse Persgemeenschap“ (Stiftung Katholische Niederländische Pressegemeinschaft) unter der Verwaltung des "Raad voor de Katholieke Pers" ins Leben. Dieser Rat hat nie funktioniert, so daß der „Versäulungseifer" nicht bis zum bitteren Ende der katholischen Presseorganisationen gewütet hat. Für die Ausbildung katholischer Journalisten wurde 1947 in Nimwegen das "Instituut voor de Katholieke Journalistiek“ (Institut für Katholische Journalistik) gegründet ${ }^{\theta}$. Da vor 1940 Bischöfe und Leser immer noch gelegentlich über bestimmte Anzeigen, besonders für Damenunterwäsche, geklagt hatten, richtete die KNDP 1946 ein Büro ein, das die Zulässigkeit von Anzeigen zu beurteilen hatte. Das Büro bestand aus dem geistlichen Berater der KNDP und dem Sekretär derselben Organisation. Ihnen zur Seite stand ein Beratergremium aus sieben Anzeigenabteilungsleitern von Tageszeitungen. Die Commissie van Samenwerking voor de Katholieke Pers ereiferte sich, Statuten für die „Stichting Centraal Bureau voor AdvertentieAangelegenheden der Katholieke Pers" (Stiftung Zentralbüro für Anzeigenfragen der Katholischen Presse) zu entwerfen; dieses Büro sollte die Zulässigkeit von Anzeigen für die gesamte katholische Presse beurteilen, scheint aber nie funktioniert zu haben. Der 1951 als Nachfolger von Pater Heymeijer zum "aalmoezenier" der katholischen Presse ernannte Mitbruder von ihm, M. Bogaartz, sandte am 24. Februar 1956 von neuem einen bereits sieben Jahre früher zustande gekommenen Rundbrief aus; darin stand unter anderem, daß Anzeigen, die sich auf Unterhaltung bezogen, in der Karwoche nicht publiziert werden dürften.

In den Statuten des "Katholieke Nederlandse Journalisten-Kring “ wurden ausdrücklich die katholischen Grundsätze als Richtschnur für das katholische Pressewesen hingestellt. An Nachdenken darüber fehlte es nicht. Das geschah mit Hilfe von Besinnungswochenenden, bei denen Gastredner sich über Themen verbreiteten, die mit der katholischen Journalistik zusammenhingen, und Kirche, Mission und Glauben im Verhältnis zur katholischen Journalistik ${ }^{\mathbf{1 0}}$ oder die spezifische Aufgabe des katholischen Journalisten zum Gesprächsthema hatten ${ }^{11}$. Bischöfe wurden eingeladen, vor dem Forum der katholischen Journalisten über die Beziehungen zwischen der katholischen Presse und der kirchlichen Obrigkeit zu sprechen ${ }^{12}$. Ubrigens war es ein Laie, Professor L. J. Rogier auf der Spitze seines Ruhms, der noch ein wenig früher als die Bischöfe das Verhältnis der katholischen Presse zum Episkopat auf die bei ihm bekannte, freimütige und kritische Weise behandelte. Bei einem Diskussionstag iber die öffentliche Meinung in Kirche und katholischer Presse am 19. Februar 1957 legte Rogier dar, daß die Emanzipation der Katholiken allmählich einen Stand erreicht habe, in dem die katholische Information, auch seitens der kirchlichen Obrigkeit, nicht genügend berücksichtigt werde. Indem er bemerkte, daß die katholische Presse in den Niederlanden als Kampfmittel zur Selbstverteidigung geboren sei, fragte er dann auch, inwiefern es gut wäre, in der alten Kampfmentalität $z u$ verharren, die einen gekünstelten Eindruck von "de katholieke eenheid van opinie“ (der katholi- 
schen einheitlichen Meinung) mache ${ }^{13}$. Kurze Zeit später, am 12. Mai 1957, plädierte Msgr. W. M. Bekkers, damals noch Bischof-Koadjutor von 's-Hertogenbosch, für "professionelle Beziehungen zwischen Presseleuten und Vertretern der Kirchenführung " ${ }^{14}$. Ende 1958 legte eine vom KNJK gebildete Kommission einen Bericht über das Verhältnis der kirchlichen Obrigkeit zur Presse vor; hierin waren auch einige Fälle listenmäßig erfaßt, in denen kirchlicherseits zu wenig Offenheit beachtet und $z u$ wenig Information gegeben worden war $^{15}$. Andere Gelegenheiten, sich auf die katholische Journalistik zu besinnen, waren das fünfzigjährige Bestehen der Organisation katholischer Journalisten im Jahre $1952^{16}$, die Jahrhundertfeier der Wiedererrichtung der bischöflichen Hierarchie im Jahre 195317, der Hirtenbrief der Bischöfe über die Katholiken und das öffentliche Leben aus dem Jahre 1954, der den Katholiken unter anderem das Lesen sozialistischer Tageszeitungen verbot, und schließlich die unterschwellig stets vorhandene Diskussion über die Ausbildung katholischer Journalisten $^{18}$.

Beliebt war die Frage nach der katholischen Einheit und in engem Zusammenhang damit die Frage, inwieweit die katholische Presse unabdingbar die „Katholieke VolksPartij" (KVP = Katholische Volkspartei) unterstützen müsse. Im Jahre 1954 - dem Jahr des genannten sehr umstrittenen und inzwischen sogar teilweise zurückgenommenen Hirtenbriefs - gab eine Arbeitsgruppe des KNJK einen Bericht über die katholische Presse und das Problem der katholischen Einheit heraus ${ }^{19}$. Darin wurde unumwunden festgestellt, daß die katholische Presse Resonanzboden, Sprachrohr und Erzieherin des katholischen Volksteils sei, daß sie eine klare Aufgabe hinsichtlich des Problems der katholischen Einheit auf sozialem und politischem Gebiet habe und daß es vor allem ihre Pflicht sei, diesen Einheitsgedanken mit allen Mitteln zu fördern. Als Argument wurde unter anderem die folgende, bereits Jahrzehnte lang erprobte Aussage vorgestellt: „Streitereien und Meinungsverschiedenheiten unter Katholiken, rücksichtslos in die Presse getragen, werden Andersdenkenden zurecht die herabwürdigende Bemerkung entlocken: Seht, wie sie einander herunterputzen." Ein hier ausdrücklich anzumeldendes Verdienst der katholischen Journalisten scheint uns zu sein, daß sie sich immer von neuem Rechenschaft gaben über das, womit sie sich befaßten, befassen wollten und befassen sollten. Dadurch, daß sie sich darauf besannen, bereiteten sie sich unseres Erachtens in den fünfziger Jahren auf die Jahre ungestümer geistlicher Verändenung in den sechziger Jahren vor. Sie konnten dadurch auf angemessene Weise ihre heikle Aufgabe in Jahren erfüllen, in denen viele Intellektuelle unter den Katholiken aus Angst vor dem, was kommen könnte, oder aus Verdruß über das, was verloren ging, in eine starre konservative Haltung zurückfielen oder sich total ihrer katholischen Vergangenheit entfremdeten.

Der katholische Journalist der fünfziger Jahre war nicht nur der „Wächter in der $\mathrm{Nacht}^{\alpha}$, custos in nocte ${ }^{20}$, der keinen Schlaf zu kennen schien und jeden Abend die Zinnen der katholischen Festung erklomm, um über das Wohlbefinden jener zu wachen, die schlafend auf seine Wachsamkeit vertrauten. Er kämpfte sich in dieser Position frei und suchte den Horizont nach neuen Entwicklungen in Kirche und Welt $\mathrm{ab}$, die der Mühe wert waren, auch die Leser aus Tagträumen und nächtlicher Ruhe hochzureißen. Das Gären der sechziger Jahre wurde nicht von Journalisten verursacht, aber durchaus von ihnen unter das Publikum gebracht, mit Kommentaren begleitet und gewertet, nicht zuletzt gerade von katholischen Journalisten, die zum größten Teil in der geschlossenen Nachkriegsgesellschaft ihre Journalistenlaufbahn erst begonnen hatten. 


\section{Der Bewußtwerdungsprozeß nach der Fusion von "De Tijd“ und "De Maasbode"}

In den Jahren nach der Befreiung fanden eine Reihe Ereignisse statt, die wir als Marksteine in der Entwicklung ansehen müssen. Wir werden sie sehr verkürzt besprechen. In kleinem Kreis von Eingeweihten wurde im September 1952 nicht ohne Furcht und Ärgernis weitererzählt, daß R. A. van Puyenbroek, ein katholischer Industrieller in Goirle, der mit der politischen Linie der "Katholieke Volks-Partij“, die mit der sozialistischen „Partij van de Arbeid“ (Partei der Arbeit) koalierte, nicht einverstanden war, für den Betrag von gut sechstausend Gulden Miteigentümer der neutralen und infolge der Kriegsvengangenheit wenig Sympathie genießenden Zeitung "De Telegraaf" geworden war. Man hatte das Empfinden, daß Van Puyenbroek "De Telegraaf" (Auflage 120.000 Exemplare im Jahre 1952, und im Jahre 1974 mit gut 700.000 Exemplaren die größte Zeitung) einsetzen wollte, um einen Damm gegen die Verstaatlichungstendenzen aufzurichten, die nach seiner Meinung bei der PvdA bestanden. Von der Einstellung des Meinungswochenblatts "De Nieuwe Eeuw" (gegründet 1917) im Jahre 1956 spricht man nicht mehr; das gilt sicher nicht für die Fusion von „De Tijd“ und „De Maasbode“ im Jahre 1959, bei der die letztgenannte Tageszeitung Eigentum von NV De Spaarnestad, der Eigentümerin von „De Tijd“, wurde. Auf dem Hintergrund der Kommission Romme-Asberg und der Kommission De Quay braucht es nicht zu verwundern, daß der Episkopat der durch die roten Ziffern von „De Maasbode“ erzwungenen Fusion sehr zugeneigt war ${ }^{21}$. In der Welt der regionalen Tagespresse verloren in den sechziger Jahren viele katholische Tageszeitungen ihre Selbständigkeit, und eine Anzahl von ihnen wurde eingestellt. Um die einzige regionale katholische Tageszeitung im Norden des Landes, "Ons Noorden $^{\text {", }}$ zu erhalten, wunde eine Aktion durchgeführt, die sich als vergeblich erwies. Vom 1. April 1964 an wurde die Tageszeitung eingestellt ${ }^{22}$; ein Wochenblatt mit viel kirchlich-religiöser Information, herausgegeben unter dem Titel "Het Noorden", lebte nur zwei Jahrgänge lang. Nicht unbeachtet blieb, daß „De Volkskrant“ 1964 das Wort "katholiek" im Untertitel "Katholiek Dagblad voor Nederland" fallen ließ. Noch im selben Jahr schied der Chefredakteur, der den journalistischen Erfolg von "De Volkskrant" nach dem Krieg begründet hatte, J. M. Lücker, aus, wahrscheinlich auch weil er mit der vorgenommenen Kursänderung nicht einverstanden war. In den zehn Jahren nach dem Ausscheiden von Lücker entwickelte sich „De Volkskrant $^{\text {" }}$ von einer eng mit der katholischen Arbeiterbewegung verbundenen Zeitung für Arbeiter und Mittelschicht zu einer linksprogressiven, unabhängigen Tageszeitung, die auch nichtkatholische Leser zu gewinnen suchte. Katholischen Nachrichten und Kommentaren wurde Beachtung geschenkt, sofern man meinte, daß sie auch für Nichtkatholiken von Interesse sein könnten.

Noch im selben Jahr 1964 befaßte sich eine Kommission „Kerk en publiciteit" (Kirche und Publizität) mit der Verbesserung des Verhältnisses zwischen Episkopat und Massenmedien, was letztlich auf die Ernennung eines Informationsfunktionärs, eines Pressesprechers der Niederländischen Kirchenprovinz Ende 1972 hinauslief²3. Dieselbe Kommission untersuchte auch die Frage eines Zensors bei einer katholischen Tageszeitung, ließ sie aber weiterhin auf sich beruhen. Noch am 13. September 1961 wurde der letzte Zensor von "De Volkskrant" ernannt; zehn Jahre später erklärte der Chefredakteur dieser Zeitung jedoch in einem Interview, er wisse nicht, wer die Funktion im Augenblick wahrnehme: aufheben kann man eine kirchenrechtlich geregelte Funktion nicht, aber vergessen kann man sie. 
Die genannten und andere hier nicht erwähnte Vorgänge stellten die Verleger katholischer Tageszeitungen 1964 vor die Frage, ob die katholische Tagespresse nicht ernsthafter in ihrem Sein bedroht sei als die nichtkatholische. In einer Note, die unter anderem über die "Analecta" - die offiziellen Mitteilungsblätter der Bistümer - weit verbreitet wurde, stellte die KNDP nicht ohne Bedauern fest, daß eine Mentalitätsveränderung eingetreten sei. "Hiermit" - so die Note - "wird gesagt, daß sich auf der ganzen Linie eine Verflachung im katholischen Denken zeigt; diese findet ihren Ausdruck in der abnehmenden Bereitschaft der Katholiken, eine katholische Tageszeitung zu lesen. Die veränderte Mentalität der katholischen Leser, unter ihnen auch vieler Geistlicher, bringt es mit sich, daß man sich für einen Grad von Offenheit entscheidet, der das Klima aufhebt, in dem katholische Presse gedeihen kann. Der katholische Leser abonniert nicht mehr wie früher ein katholisches Blatt aus einer Art Pflichtgefühl oder aus Solidaritätsdenken. Im Gegenteil zeigt sich immer mehr, daß trotz der im allgemeinen guten Qualität der katholischen Tageszeitungen viele Katholiken - vor allem die jüngere Generation zeigt die besagte Mentalitätsveränderung - eine nichtkatholische Zeitung von gleicher oder sogar minderer Qualität wählen. “24 Die KNDP erkannte, was sie den „relativen Rückgang" der katholischen Tagespresse nannte, indem sie davon ausging, daß Wachstumsstillstand auch Rückschritt gegenüber den nichtkatholischen Tageszeitungen bedeute (siehe Tabelle 2). Sie fühlte sich darin bestärkt durch eine soeben publizierte Analyse der Existenznot der katholischen Presse ${ }^{25}$.

Tabelle 2: Auflageziffern der katholischen und nichtkatholischen Tageszeitungen in den Niederlanden von 1955 bis 1964 :

\begin{tabular}{|c|c|c|c|c|c|c|}
\hline & $\begin{array}{l}\text { Verkaufte } \\
\text { Auflage } \\
\text { der kath. } \\
\text { Tages- } \\
\text { zeitungen }\end{array}$ & Index & $\begin{array}{l}\text { Prozent- } \\
\text { satz der } \\
\text { Gesamt- } \\
\text { auflage } \\
\text { der } \\
\text { niederl. } \\
\text { Tages- } \\
\text { zeitungen }\end{array}$ & $\begin{array}{l}\text { Verkaufte } \\
\text { Auflage } \\
\text { der nicht- } \\
\text { katholischen } \\
\text { Tages- } \\
\text { zeitungen }\end{array}$ & Index & $\begin{array}{l}\text { Prozent- } \\
\text { satz der } \\
\text { Gesamt- } \\
\text { auflage } \\
\text { der } \\
\text { niederl. } \\
\text { Tages- } \\
\text { zeitungen }\end{array}$ \\
\hline 1955 & 807.807 & 100 & 29,9 & 1.890 .785 & 100 & 70,1 \\
\hline 1956 & 831.079 & 102,8 & 29,9 & 1.949 .895 & 103,1 & 70,1 \\
\hline 1957 & 844.479 & 104,5 & 29,4 & 2.028 .343 & 107,3 & 70,6 \\
\hline 1958 & 853.205 & 105,6 & 29,3 & 2.047 .305 & 108,3 & 70,7 \\
\hline 1959 & 875.257 & 108,3 & 29 & 2.147 .707 & 113,6 & 71 \\
\hline 1960 & 894.969 & 110,7 & 28,7 & 2.220 .361 & 117,4 & 71,3 \\
\hline 1961 & 928.925 & 114,9 & 28,8 & 2.296 .122 & 121,4 & 71,2 \\
\hline 1962 & 963.664 & 119,2 & 29 & 2.355 .536 & 124,6 & 71 \\
\hline 1963 & 961.951 & 119 & 28,4 & 2.419 .243 & 127,9 & 71,6 \\
\hline 1964 & 956.815 & 118,4 & 28,1 & 2.446 .147 & 129,4 & 71,9 \\
\hline
\end{tabular}

Quelle: Angaben des "Centraal Bureau voor Couranten Publiciteit" (CEBUCO = Zentralbüro für Zeitungspublizität), auch veröffentlicht in Marsman: a. a. O., S. 244. 
Auch ist weiterhin merkwürdig, daß eine durch die Note der KNDP in die Wege geleitete Studie des Nimweger Soziologen G. W. Marsman in dessen Dissertation (1967) sich sehr positiv, aber tatsächlich auch rein spekulativ über die Zukunft der katholischen Tagespresse ausließ ${ }^{26}$. Marsman folgerte, daß die katholische Tagespresse in ihrem Fortbestand und ihrer Weiterentwicklung nicht in Gefahr kommen werde, solange sie journalistische Qualität zeigen und sich weiter vervollkommnen würde. Marsman behauptete ohne weiteres entschieden, daß das katholische Publikum „trotz und zum Teil sogar gerade zufolge der Veränderungen in der ,Versäulung“ einer katholischen Zeitung den Vorrang geben würde “27. Hatte die Note der KNDP auch erst einige Jahre später als viele katholische Journalisten die Zeichen der Zeit verstanden, so bot die wissenschaftliche Analyse aus dem Jahre 1967 ein naivoptimistisches Zukunftsbild für die katholische Tagespresse an, an das die von der Untersuchung Marsman betroffenen katholischen Verleger - wie die Reaktionen zeigen - selbst nicht mehr glaubten ${ }^{28}$. Marsman hatte in seiner Untersuchung die Tendenz zu größeren Einheiten im Gesamtbereich der Tagespresse und den damit zusammenhängenden Prozeß der Pressekonzentration nicht berücksichtigt und ebensowenig die Veränderungen in der niederländischen Gesellschaft, an denen die Katholiken in ganz anderer Weise zunehmenden Anteil hatten. Ein Jahr nach dem Erscheinen seiner Dissertation bezeugte Marsman von neuem, daß das Verschwinden katholischer Tageszeitungen nichts mit dem echten "Entsäulungsprozeß“ zu tun habe; die Frage, wie der Funktionsverlust der katholischen Presse nun wirklich erklärt wenden kann, hat er also nicht hinreichend beantwortet ${ }^{20}$.

Rooij teilte in seinen Publikationen die niederländische Tagespresse in Gesinnungszeitungen (katholisch, protestantisch-christlich, sozialistisch und liberal) und sogenannte „neutrale“ Zeitungen ein ${ }^{90}$. Unter Gesinnungsblättern müssen - nach Rooij $\mathrm{zweifellos}$ bis in die sechziger Jahre Zeitungen verstanden werden, die sich öffentlich zu einer weltanschaulichen und/ader politischen Grundlage bekennen und - so möchten wir hinzufügen - auch als solche vom Leserpublikum anerkannt werden. "Neutral“ muß man auffassen im Sinn von nicht politisch und/oder weltanschaulich gebunden; die politischen Auffassungen können wechseln von links-liberal bis rechtskonservativ. Das Bestehen von Gesinnungsblättern ist unumgänglich mit dem Bestehen einer weltanschaulich und politisch pluriformen Gesellschaft mit freier Meinungsäußerung verbunden. Die nach 1960 sich entwickelnde Gesellschaft der Niederlande stellte Probleme: die Diskussion und Auseinandersetzung um das Problem der Funktions- und Standortbestimmung von Gesinnungsblättern war nicht mehr freibleibend - wie zuvor: die gesellschaftlichen Veränderungen waren bereits gegeben. Tabelle 3 zeigt, wie stabil die Verhältnisse zum Beispiel zwischen 1955 und 1964 noch waren:

Tabelle 3: Die Position der Gesinnungsblätter, ausgedrückt in Prozenten der Auflage aller bei der Vereinigung „De Nederlandse Dagbladpers“ (Die Niederländische Tagespresse) angeschlossenen Tageszeitungen (außer "De Waarheid “) ${ }^{31}$

\begin{tabular}{lcc}
\hline Gesinnung & im Jahre 1955 & im Jahre 1964 \\
katholisch & 26,4 & 26,8 \\
evangelisch & 8,7 & 8,2 \\
sozialistisch & 19,3 & 16,1 \\
liberal & 5,1 & 4,6 \\
\hline \multicolumn{1}{c}{ zusammen } & 59,5 & 55,7 \\
neutral & 40,5 & 44,3 \\
\hline \multicolumn{1}{c}{ Gesamt } & 100 & 100
\end{tabular}


Obwohl es bereits schwierig ist, das Verhältnis der Gesinnungsblätter zu den neutralen Blättern nach 1960 zahlenmäßig zu bestimmen, ist das nach 1964 ganz gewiß nicht mehr möglich, weil zu der Zeit sowohl die Struktur der Gesellschaft als auch der Tagespresse die Stabilität der fünfziger Jahre nicht mehr besitzen. Die Einheit der Katholiken in der Politik ging ebenfalls verloren. Die 1966 gegründete neue politische Partei „D' 66" fand auch bei vielen Katholiken Interesse; 1967 entstand die Politieke Partij Radikalen (Politische Partei der Radikalen) als Absplitterung von der Katholieke Volks-Partij (Katholische Volkspartei). Es vollzog sich eine Entkonfessionalisierung von ehedem traditionell gebundenen Wählergruppen: die Anzahl Sitze der KVP in der Zweiten Kammer sank zwischen 1963 und 1972 von 50 auf 27. Eine 1972 neu gegründete konservative katholische Partei, die „Rooms Katholieke Partij Nederland" (Römisch-katholische Partei der Niederlande), errang im Jahre 1972 einen Sitz ${ }^{32}$.

Der Prozeß der Pressekonzentration wurde auf dem Sektor der katholischen Tagespresse stänker spürbar als auf der neutralen Seite ${ }^{33}$. Im Jahre 1964 fusionierten NV De Spaarnestad („De Tijd“) und CEBEMA, der sogenannte Teulings-Konzern in Den Bosch, der u. a. regionale katholische Tageszeitungen in Nord-Brabant herausgab. Aus der Fusion entstand ein Mammutkonzern, die „Verenigde Nederlandse Uitgeversbedrijven" (VNU = Vereinigte Niederländische Verlagsbetriebe). Davon ist im folgenden Abschnitt wiederholt die Rede. Im Jahre 1964 begannen "De Volkskrant“ und „Het Parool “ (unabhängig-sozialistisch) in Amsterdam gemeinsam eine Druckerei zu betreiben; 1968 folgte eine vollständige technische und unternehmerische Integration beider Tageszeitungen; sie wurden Eigentum der damals gegründeten „NV Perscombinatie“ (Pressekombination). So etwas hielt ein Kenner und Fachmann, Prof. Dr. M. Rooij, im Jahre 1961 noch für völlig unmöglich, wie er selbst noch unlängst schrieb ${ }^{34}$. Die Vorgänge, welche die niederländische Katholische Kirchenprovinz in den letzten zehn Jahren bewegten und mehrmals heftig erschütterten, wurden auch von den ausländischen Massenmedien berichtet und kommentiert $^{35}$. Wir werden bei der Behandlung der Probleme rund um „De Tijd“ besonders auf den "Polarisierungsprozeß in der Geschenkpackung der Pluriformität "si hinweisen, der die Katholiken in den Niederlanden in mehrere Lager teilte.

\section{Die neue journalistische Formel von „De Tijd“ als supplementäre Meinungszeitung}

Ehe wir auf die jüngste Periode von „De Tijd“ eingehen, müssen wir einiges Augenmerk auf die redaktionelle Linie der Zeitung richten. Nach dem Zweiten Weltkrieg steuerte „De Tijd“ einen gemäßigt progressiven Kurs. Chefredakteur L. G. A. Schlichting, der nach der Befreiung diese Funktion wieder übernommen hatte, war ein typischer Vertreter des sogenannten „Durchbruchsgedankens“, dem zufolge die Katholiken sich nach dem Krieg nicht mehr in eine als unheilvoll geltende Isolierung zurückziehen durften. Schon in den Kriegsjahren hatte Schlichting in pseudonym und illegal erschienenen Broschüren die Notwendigkeit einer politischen Partei für Katholiken in Frage gestellt ${ }^{37}$. Nicht ohne Enttäuschung über den nach der Befreiung ausgebliebenen „Durchbruch“ verließ Schlichting Mitte Mai 1946 „De Tijd“. Sein Nachfolger, P. A. Kerstens, hielt nur anderthalb Jahre durch: er war ein Vorkämpfer der Entkolonisierung zu einem Zeitpunkt, als die Niederlande im heutigen Indonesien (dem damaligen Niederländisch-Indien) Krieg für die Erhaltung der Kolonien führten. Die Leser und die Eigentümerin von „De Tijd“ nahmen die gewagte politische Ein- 
stellung von "De Tijd“ in der Indonesienfrage nicht mit Dank entgegen. Kerstens trat zurück. Ihm folgte im Amt eine in den Augen vieler Redakteure von „De Tijd“ legendäre Gestalt: Jan Derks. Unter seiner Leitung und Inspiration wurde „De Tijd“ journalistisch ein Qualitätsblatt. In den viereinhalb Jahren, in denen Derks Chefredakteur war, wurde mit der Eigentümerin NV De Spaarnestad viel über den einzuschlagenden Kurs gestritten. Auf eine tadelnswerte Weise wurde Derks 1952 beiseite geschoben, und einige Monate später folgte eine Kursänderung in der Redaktionsführung der Nachkriegszeit. Vom 1. September 1952 bis zum 1. Dezember 1965 drückte W. A. M. van der Kallen der Redaktionsführung von „De Tijd“ seinen Stempel auf. Man kann seine Kommentare konformistisch, aber nicht kritiklos nennen, und damit haben wir bereits den Standort der Zeitung - von Feinheiten abgesehen - gekennzeichnet.

In den Nachkriegsjahren war „De Maasbode“ eine konservative Zeitung; für die noch zu erörternden Verwicklungen rund um „De Tijd“ ist es wichtig anzumerken, $\mathrm{da}$ diese konservative Lesergruppe durch die Fusion von 1959 einen nicht unbedeutenden Bestandteil der Leser von "De Tijd-De Maasbode“ - wie die Zeitung von 1959 bis Ende 1965 hieß - ausmachte. Hatte „De Tijd“ vor 1952 bereits viele konservative Leser verloren, zu Beginn der sechziger Jahre begann ein stärkerer Auszugsprozeß progressiver Leser. Außerdem stieß „De Volkskrant" 1964 in die Richtung einer Zeitung für Leser mit stark gesellschaftlich gefärbtem Engagement vor. In den Jahren, da „De Tijd“ ziemlich progressiv war, war „De Volkskrant“ nur progressiv, sofern es darum ging, die Stellung von Arbeitern und Mittelschicht zu verbessern; politisch lief die Zeitung jahrelang am Gängelband der „Katholieke Volks-Partij“, und in der Indonesienfrage nahm sie einen (auch im buchstäblichen Sinn) bewahrenden Standpunkt ein. Der 1964 bei „De Volkskrant" ausgeschiedene Chefredakteur Lücker fand eine Tätigkeit bei VNU, die neben anderen Blättern „De Tijd-De Maasbode" herausgab. Ende 1965 wurde Lücker - zusammen mit dem als progressiv zu bezeichnenden A. J. Cuppen - Chefredakteur von „De Tijd“; Van der Kallen wurde Direktor. Zu gleicher Zeit wurde auch die Herausgabe der sogenannten Kopfblätter von „De Tijd-De Maasbode“: „De Nieuwe Dag“, „Nieuwe Haarlemsche Courant", "Kennemer Dagblad“ und "Het Nieuwe Dagblad" maßgeblich geändert. Diese Nebenausgaben, die in Amsterdam, Haarlem, der Umgebung von Haarlem beziehungsweise von Rottendam erschienen, wurden eingestellt und durch Ausgaben eines Kopfblatts, nämlich „De Nieuwe Dag“, ersetzt ${ }^{38}$. Eine weitere beachtliche Veränderung der Erscheinungsform bestand in der Rückkehr zum Titel "De Tijd. Dagblad voor Nederland"; nur für die Rotterdamsche Ausgabe wurde der Kopf „De Tijd-De Maasbode“ beibehalten. Die zuvor aufgezählten Änderungen hatten zum Ziel, die seit 1963 mit jährlichen Verlusten von ungefähr drei Millionen Gulden arbeitende Zeitung rentabel oder zumindest weniger verlustbringend $z u$ gestalten. Inhaltlich wurde die Zeitung bemerkenswert verbessert, während die freiere Einstellung in Sachen von Kirche und Glauben den Redaktionskurs - ohne Aufhebens davon zu machen - änderte.

"De Tijd“ “agte den Absprung von einem traditionellen katholischen Organ hin zu einer modernen, offenen Zeitung, gemacht von einer Redaktion mit katholischem Hintergrund, was aber - so hoffte man - nicht ausschließlich von Katholiken geschätzt würde. Versöhnlichkeit und Offenheit sollten die bezeichnenden Merkmale der Zeitung werden. Der Wandlungsprozeß ging jedoch gleichzeitig langsam und schnell vonstatten: Für manche Leser ging er zu träge voran: sie stellten ihr Abonne- 
ment ein und gingen zu „De Volkskrant" über, die in einer bisweilen störend unversöhnlichen Weise weiterhin links-progressiven Kurs hielt. Andere Leser dagegen fanden, daß "De $\mathrm{Tijd}^{\text {“ }}$ ihre Vergangenheit verrate und auf eine zu progressive Weise, vor allem in Sachen der Kirche, verfuhr. Sie gingen bei dem rechts-konservativen Blatt „De Telegraaf“ vor Anker. Der Radikalismus von 1968 und der Kulturwandel der Jahre 1969 bis 1972 ließ jene Tageszeitungen und Rundfunkorganisationen Obenhand gewinnen, die sich entweder für reaktionär und/oder neutral oder aber für elitär-radikal und einseitig kritisch gegenüber Gesellschaft und Kirche entschieden. „De Tijd“ entschied sich jedoch für die „dynamische Mitte" (A. J. Cuppen), überzeugt, wie sie war, daß auch von dieser Position aus Erneuerung von Kirche und Gesellschaft möglich sei. Die Mehrheit der jungen Studentengeneration schätzten noch nicht die Abkehr von lehrmäßiger Starre und den Freiheitsraum für Zweifel und Unsicherheit; andererseits wurde die "silent majority (schweigende Mehrheit) - für diese Gruppe hätte „De Tijd“ durchaus eine attraktive Zeitung abgeben können - offenbar ungenügend erreicht. Überdies zog die am 1. November 1970 durch Fusion von „Nieuwe Rotterdamse Courant“ und „Algemeen Handelsblad" zustande gekommene neue Tageszeitung "NRC Handelsblad“ katholische Intellektuelle und liberale Unternehmer einer gewissen Oberschicht an.

Es ist nicht ganz zufällig, daß der Todeskampf von „De Tijd“ in dem Zeitraum begann, als die neue Tageszeitung „NRC Handelsblad“ vorbereitet wurde. Am 28. August 1970 teilten die Konzerne VNU (unter anderem Eigentümerin von „De Tijd“) und NDU ("Nederlandse Dagblad Unie“, unter anderem seit 1964 Eigentümerin von "Nieuwe Rotterdamse Courant" und "Algemeen Handelsblad“, später von „NRC Handelsblad ") mit, sie hätten sich zur Zusammenarbeit bei Herausgabe von "De Tijd", „Nieuwe Rotterdamse Courant" und "Algemeen Handelsblad" entschlossen ${ }^{39}$. „Es ist" - so das gemeinsam herausgegebene Kommuniqué - „beabsichtigt, daß die Zusammenarbeit journalistische, kommerzielle und technische Elemente umfassen soll." Bereits am 1. Oktober 1970 begann die technische Zusammenarbeit; an dem Tag schloß die Druckerei von „De Tijd“ und übernahm NDU den Druck. Die journalistische Zusammenarbeit schlug tatsächlich fehl. So war es zum Beispiel kein glücklicher Griff, die Sportredaktion von "De Tijd“ (ab 1. November) auch für "NRC Handelsblad“ arbeiten zu lassen. Seit Mitte der sechziger Jahre war die Sportberichterstattung von "De Tijd “ berühmt ${ }^{40}$; da man diesen so anerkannten Teil der Zeitung dem Konkurrenten überließ, verlor „De Tijd“ nicht allein ein Stück ihrer selbst, sondern schwächte auch ihre Konkurrenzposition. Der erfolgreichste Teil der journalistischen Zusammenarbeit aus dem Blickwinkel von „De Tijd“ war die gemeinsame Entsendung von Auslandskorrespondenten.

Als die Einsparungen enttäuschten, kündigte VNU am 14. Mai 1971 an, der Konzern sehe es nicht länger als zu verantworten an, das Unternehmen der Zeitung fortzusetzen. Was danach geschehen ist, kann als einmalig in der niederländischen und der ausländischen Pressegeschichte hingestellt werden: die Redaktion unternahm eine großangelegte Aktion, um mehr Abonnenten zu gewinnen, und mobilisierte die öffentliche Meinung. So wie es vierzig Jahre vorher der Fall gewesen war, wurde eine Beratergruppe „Vrienden van De Tijd“ (Freunde von "De Tijd ${ }^{\star}$ ) gegründet. Es wurden Geldvorräte zusammengetragen, die es ermöglichen sollten, potentielle Abonnenten auf "De Tijd“ aufmerksam zu machen. In der Nacht vom 14. auf den 15. Mai 1971 druckte die Redaktion mit Hilfe und Einverständnis des Personals aus Verwaltung und Setzerei auf die Titelseite nur zwei Sätze: (in sehr großen 
Lettern): „WIJ GAAN DOOR MET DE TIJD“ (Wir fahren fort mit De Tijd) und in kleinen Lettern "Neem een abonnement" (Nehmen Sie ein Abonnement). „Oder nehmen Sie ein zweites. Tun Sie es schnell. Sofortige Hilfe ist doppelte Hilfe."

Die Antwort war überwältigend: als die Rettungsaktion begann, zählte die Zeitung 87.000 Abonnenten, und vor Ende 1971 kamen 25.000 neue hinzu. Die anderen Tageszeitungen und Rundfunkorganisationen reagierten im allgemeinen mit Sympathie auf die Rettungsaktion ${ }^{41}$. Innerhalb VNU entwickelte eine Arbeitsgruppe unter Leitung von B. P. A. R. Bakker einen Plan für eine Tageszeitung „De Tijd“ neuen Stils. Am 4. Oktober 1971 brachte die Arbeitsgruppe einen Bericht vor iden Verwaltungsrat von VNU, in dem für „eine neue Zeitung plädiert wurde, die in der Tradition von $\mathrm{De} T \mathrm{~T} i \mathrm{j}$, aber frei von beengenden Banden der Vergangenheit, für den madernen, intelligenten Leser publiziert, der gesellschaftlich engagiert, politisch und kulturell, sozial-ökonomisch, weltweit an Wissenschaft, Information und Belehrung, Meinungsbildung und Kommentar rund um das Tagesgeschehen ohne Vorurteile, aber aus einer allgemein christlichen Lebenshaltung interessiert ist". Chefredakteur Cuppen stellte im Rahmen des Bakker-Plans die redaktionelle Leitlinie auf und bekam daraufhin das Placet der gesamten Redaktion. Im Bakker-Plan war auch vorgesehen, daß alle regionalen/lokalen Ausgaben abgestoßen würden und daß die eigene Setzerei geschlossen werden sollte. Die neue Leitlinie von „De Tijd“ würde nach den derzeitigen Berechnungen mit 60.000 zahlenden Abonnenten und einem täglichen freien Verkauf von 5.000 Exemplaren auskommen. Bezeichnend für die redaktionelle Leitlinie von Cuppen war, daß „De Tijd“ endgültig aufhören sollte, eine Nachrichtenzeitung zu sein: „De Tijd" sollte sich als Meinungszeitung an die Leser richten, die "De Tijd“ als zusätzliche Zeitung abonnieren wollten ${ }^{42}$. Anstelle des Adjektivs "katholiek“ wurde das Wort "christelijk“ (christlich) bevorzugt, weil jahrelang der Hinweis "katholieke krant" (katholische Zeitung) als Verkaufsargument gebraucht und mißbraucht worden war ${ }^{43}$. „De Tijd “ plante jedoch nicht, ihre Herkunft zu verleugnen und machte das wiederholt deutlich, unter anderem in einem bissigen Kommentar der Chefredaktion, nachdem "De Telegraaf“ auf der Titelseite gebracht hatte, „De Tijd“ würde ihren „rooms-katholieke karakter" aufgeben $^{4}$.

Am 1. Dezember 1971 bekam „De Tijd" eine neue Direktion, und einer der Chefredakteure, Lücker, schied aus, nachdem er sich bereits einige Monate nicht mehr um die Redaktion der Zeitung gekümmert hatte. Die Setzerei von "De Tijd“ wurde am 1. Mai 1972 geschlossen, das Gebäude, in dem man seit 1904 gearbeitet hatte, wurde verkauft, und die Redaktion kam in einem Gebäude von NDU unter, in dem die Zeitung künftig auch von NDU gesetzt und gedrudkt wurde. Die neue Leitlinie nahm langsam, aber sicher Gestalt in den redaktionellen Spalten an. Es dauerte jedoch noch bis zum 1. September 1972, ehe man Ersatz für den zweiten Chefredakteur fand. Ernannt wurde $H$. van Run, der nach fünfjähriger Tätigkeit an der "School voor de Journalistiek" (der niederländischen Journalistenschule), in den praktischen Zeitungsbetrieb zurückkehrte; von 1948 bis 1963 war er Chefredakteur eines Kopfblatts von „De Tijd“ ("Nieuwe Haarlemsche Courant") gewesen und danach politischer Redakteur von „De Tijd“ (-„De Maasbode“). Vom 31. Dezember 1973 an - als Cuppen die Chefredaktion von "De Tijd“ niederlegte ${ }^{45}$ bis zur Einstellung der Zeitung am 31. August 1974 war Van Run alleiniger Chefredakteur. 


\section{Die Tageszeitung „De Tijd auf dem Weg zum Ende}

Obwohl die Abonnenten eine große Rolle bei der Rettungsaktion von 1971 gespielt hatten, war eine Teilnahme an der redaktionellen Gestaltung der Zeitung im neuen Stil in gar keiner Form vorgesehen. Wie eine solche Art der Mitsprache hätte gestaltet werden sollen, ist übrigens eine Frage, die vorläufig niemand beantworten kann. Rasch zeigte sich jedoch, daß eine große Anzahl Abonnenten "De Tijd" verdächtigten, von einer mittleren Position auf eine Position links von der Mitte eingeschwenkt zu sein. Die Beschwerdebriefe böser und enttäuschter Leser wurden großzügig in der Rubrik „Brieven van lezers" (Leserbriefe) abgedruckt. Viele Briefe spiegeln eine gehässige Mentalität wider, als ob „De Tijd“ die Schuld an allen Veränderungen, besonders innerhalb der Kirche, trüge. Am 17. August 1973 beklagte ein Leser sich (zu Unrecht) darüber, daß der Spruch "Dieu et mon droit“ (Gott und mein Recht) beinahe nicht mehr im Titel zu entdecken sei; die Redakteure sollten sich nur schnell nach Ersatztätigkeiten umschauen, weil „De Tijd“ rasch aus der Zeit geriete. Bis in die letzten Monate ihres Bestehens hin bemühten sich einige Briefschreiber, der Redaktion mit eingesandten Leserbriefen deutlich $\mathrm{zu}$ machen, was unter einer

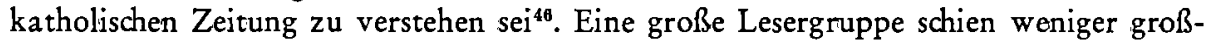
herzig denken zu wollen, als man gehofft hatte. Der seit 1969 noch mehr oder minder unsichtbare und seit 1972 sehr offene Polarisierungsprozeß unter den niederländischen Katholiken spielte „De Tijd“ einen Streich: Kenner der Situation stellten die bedrückende Frage, ob denn noch eine Uberlebenschance für eine Zeitung bestehen könne, die sich nicht ausdrücklich für links oder rechts entscheiden, sondern eine Forumsfunktion erfüllen wolle, um die Kommunikation zwischen den Katholiken untereinander und ihrer Umwelt in Gang zu bringen und zu halten. Trotz der Tatsache, daß jede der drei Gruppen wiederholt das Gegenteil bezeugte, hätten weder die Konservativen noch die Gruppe der Mitte noch auch die Progressiven das Weiterbestehen als einzelne garantieren können. Außerdem hatte man sich in dem neuen Konzept bewußt für die Dialogfunktion von einer Position der Mitte aus entschieden. Besonders bezeichnend hierbei ist, daß „De Tijd" in keinem Augenblick versuchte, in dem Kommerzialisierungsprozeß mitzuschwimmen, der das Funktionieren der Massenmedien in der von Weltanschauungspluralismen geprägten demokratischen westeuropäischen Gesellschaft gemeinhin bedroht.

Zum Verlust der konservativen Leser kam der Abgang der Abonnenten der eingestellten Nebenausgaben, die nach einer neutralen Regionalzeitung griffen. Der Verlust einiger zehntausend Abonnenten dieser letzten Kategorie war jedoch im Bakker-Plan bereits berücksichtigt. Zu der Polarisierung auf kirchlich-religiöser Ebene kam die Polarisierung im politischen Bereich: die christlichen Parteien (Katholieke Volks-Partij, Anti-Revolutionaire Partij und Christelijk-Historische Unie) suchten einander anzunähern im Christen Democratisch Appèl (CDA $=$ Christdemokratischer Appell), schienen aber konfessionell doch nicht so leicht übereinkommen zu können; die CHU vertrat zu stark die Seite der liberalen Volkspartij voor Vrijheid en Democratie (VVD = Volkspartei für Freiheit und Demokratie), die wie die CHU in der Opposition sitzt. Obgleich die führenden Männer des CDA ausgiebig in „De Tijd“ zu Wort kamen, ließ die Zeitung sich doch nicht verleiten, eine Art Parteiorgan zu werden.

Ende 1973 erlebte „De Tijd“ eine zweite Krise. Die fianziell-ökonomische Situation für die gesamte niederländische Tagespresse erschien damals wegen der hochschnellenden Papier-Preise und der Probleme der Energiekrise sehr ungünstig. Hinterher 
erwies sich die Situation für die meisten Zeitungen immer noch besser als erwartet, jedoch nicht für „De Tijd“" ${ }^{47}$. Zudem sank die Abonnentenzahl unter 60.000 , die kritische Grenze des Bakker-Plans von 1971. Viele neue Abonnenten schienen mehr in cinem Aufwallen von Solidarität mit der Redaktion als aus Liebe zum Inhalt der Zeitung hinzugestoßen zu sein. Die konservativen Leser sprangen in größerer $\mathrm{Zahl}$ $a b$, als neue, vor allem jüngere Leser, hinzukamen. Das Anzeigenaufkommen blieb hinter den Erwartungen zurïck. Journalistisch gesehen schien es obendrein nicht leicht, mit fast derselben Redaktion eine Meinungs- statt einer Nachrichtenzeitung zu machen. Die Erweiterung der Redaktion mit neuen Kräften erwies sich als schwierig, Journalisten-Kollegen schüttelten den Kopf über das Abenteuer von „De Tijd“ und sprachen abschätzig oder besorgt über „De $\mathrm{T}_{i j d}$ “ als täglich erscheinendes Wochenblatt. Im Oktober 1973 ließ VNU wissen, daß die Zeitung denn doch cingestellt werden müsse. Später erklärte VNU, daß es nicht die Aufgabe eines Unternehmens sei, eine "gesellschaftliche Institution“ wie „De Tijd“ dauernd zu unterstützen. VNU soll in einem Zeitraum von zehn Jahren ein Defizit von 25 Millionen Gulden (offiziös genannt) getragen haben. Das Experiment wurde als mißglüdkt angesehen.

Am 24. Dezember, dem Tag vor Weihnachten, wurde dem Personal mitgeteilt, daß "De Tijd“ eventuell mit staatlicher Unterstützung auch innerbalb der VNU weiter betrieben werden könne. Am 10. Januar 1974 teilte die VNU - nach intensiver Uberlegung mit den staatlichen Stellen, besonders dem Minister für Kultur, Freizeitgestaltung und Sozialordnung, H. van Doorn - in einem Kommuniqué mit: „Staatliche Stellen und VNU werden zusammen bis zu einem Höchstbetrag von drei Millionen Gulden die Betriebsverluste im Verhältnis Zweidrittel/Eindrittel tragen, während die VNU auch die nichtfesten Nebenkosten auf ihre Rechnung nimmt. Überdies muß eine Mindestauflage von 55.000 bezahlten Exemplaren gehalten werden. ${ }^{\text {“48 }}$ Minister Van Doorn griff mit seinen Zusagen an "De Tijd“ der von ihm versprochenen Note über die gesamte Medienpolitik und das Wirksamwerden des „Bedrijfsfonds voor de Pers" (Betriebsfonds für die Presse) vor ${ }^{49}$. Am 5. Februar wurde ihm in der Zweiten Kammer während einer Sonderdebatte über diese Unterstützung stark zugesetzt. Viele Zeitungen, voran „De Telegraaf“, sprachen sich gegen die Unterstützung aus und bezeichneten sie als Konkurrenzverfälschung. Die liberale Oppositionspartei VVD sprach sich sehr negativ über die Pressepolitik der progressiven Regierung Den Uyl aus. Die Zweite Kammer ließ den Minister nicht im Stich, forderte aber, daß er rasch den "Bedrijfsfonds" einrichten solle und $\mathrm{daß}$ bis dahin keine Zusage mehr an ein in Not befindliches Tages- oder Meinungswochenblatt gegeben werden dürfe. Das Glüdksgefühl über dies zweite „narrow escape“ von „De Tijd“ war nur von kurzer Dauer. Im Frühjahr zeigte sich, daß der Abonnentenbestand weiter absank und daß die Verluste den mit den staatlichen Stellen vereinbarten Höchstbetrag übersteigen würden. Allen Gerüchten wurde am 28. Juni ein Ende gesetzt: in der Ausgabe vom 29. Juni 1974 mußte "De Tijd" ihr eigenes Totenlied anstimmen. Die VNU scheint die zugesagten Staatsgelder nicht abgerufen zu haben. Vom 1. September an sollte jedoch ein neues Wochenblatt erscheinen, gemacht von zwölf Redakteuren der Tageszeitung. Der technische Betrieb der NDU, wo „De Tijd“ gesetzt und gedrudkt wurde, wurde teils liquidiert. "Bisweilen fällt auch im Sommer ein Blatt“, hieß der Kommentar in der kritischen Rubrik der Wespe in "De Tijd“50. "NRC Handelsblad“ wurde in "De Tijd“ auf feinsinnige Weise getadelt wegen der Bemerkung, daß die zum Sterben verurteilte Zeitung den Sprung von einem traditionell katholischen Organ zu einer offenkatholischen Zeitung nicht geschafft habe. Die Chefredaktion von "De Tijd“ entgegnete, daß es der Redaktion durchaus gelungen sei, den Sprung 
zu tun, daß aber die Leser darauf nicht hinreichend positiv reagiert hätten ${ }^{51}$. In den Leserbriefen spürte man manchmal den Unwillen über die Haltung, die die Redaktion gegenüber den Lesern einnähme. In der letzten Nummer von „De Tijd“ erklärten sowohl Chefredakteur $\mathrm{H}$. van Run als auch Ex-Chefredakteur A. Cuppen auf überzeugende Weise, daß „De Tijd“ keine nur meinungsbestätigende Zeitung habe sein wollen und können ${ }^{52}$; auch wenn "De Tijd" sich mit der Denkwelt eines bestimmten Teils der Leser hätte konformieren wollen, wären große Lesergruppen mit einer anderen Einstellung abgeschwenkt. Lesermitsprache bei der Redaktionsführung hätte in diesem Fall auch keine Lösung bieten können.

\section{Resultate einer Untersucbung über die Leser von „De Tijd" und Scblußfolgerung}

$\mathrm{Zu}$ dem Zeitpunkt, als beinahe sicher war, daß „De Tijd“ als Tageszeitung eingestellt würde, wurden die Ergebnisse einer seit dem 1. September 1972 durchgeführten "Mediumonderzoek dagblad ,De Tijd“" (Medienuntersuchung Tageszeitung ,De Tijd') bekannt; die Uitgeverij De Tijd BV (Verlag De Tijd) hatte dazu einen Auftrag an die Fachgruppen Kommunikatiewetenschap en Algemene Sociologie van de (evangelische) Vrije Universiteit in Amsterdam erteilt ${ }^{53}$. Die schriftlich festgelegten redaktionellen Zielsetzungen von „De Tijd“ wurden als Ausgangspunkt genommen für einen Vergleich zwischen dem Inhalt der Zeitung und den Auffassungen und Erwartungen der Leser. Die Bindung der Leser an "De Tijd" stand in dem Untersuchungsvorhaben zentral. Eine der Schlußfolgerungen der Untersuchung lautete, daß sich „De Tijd", "NRC Handelsblad" und "Trouw" (evangelisch) in Punkten wie Hintergrundinformation, Sport, Außenpolitisches Geschehen und Beobachtung von Demokratisierungsaktionen wenig unterschieden; dasselbe gelte für das Nuancierungsmaß der genannten überregionalen Tageszeitungen, was interessant ist, wenn man im Licht der angekündigten Gesamtmedienpolitik die Vielfalt der Presse ins Auge faßt. "De Tijd“ stand im Jahre 1972, gemessen auf einer Skala von 1 (sehr progressiv) bis 7 (sehr konservativ), auf 2,9, also links der Mitte, „NRC Handelsblad“ auf 2,7 (diese Zeitung war gegenüber dem Vorjahr deutlich nach links gerückt) und "Trouw auf 4,9 (diese Zeitung war deutlich nach rechts gerüdkt, was mit der Fusion von

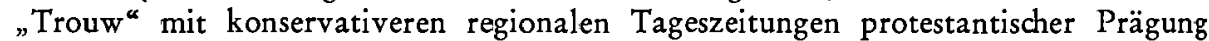
zusammenhängt). Progressive Leser schienen im allgemeinen eine größere Bindung an "De Tijd“ zu haben als konservative Leser, die weniger bereit waren, abweichende Meinungen zu verkraften. Bei vielen Ergebnissen der Untersuchung ist zu bedenken, daß der „Klärungsprozeß “ des Abonnentenbestandes im Zeitraum der Untersuchung noch nicht abgeschlossen war; Abgang und Zugang hatten sich noch nicht konsolidiert. Das gilt natürlich auch für die qualitative Profilskizze des Lesers von "De Tijd" im Schnitt. Die katholischen Leser (88 Prozent) schienen sich kirchlich gemäßigt konservativ und politisch gemäßigt progressiv zu verhalten. Verglichen mit dem Niederländer im Schnitt verhielten sich die Leser von „De Tijd“ jedoch konservativer. Von den Lesern schienen noch 43 Prozent bei den letzten Wahlen für die Katholieke Volks-Partij gestimmt zu haben. Unter den neuen Lesern war die Anzahl KVPWähler nach dem Untersuchungsbericht jedoch bedeutend niedriger. Dreiviertel der Leser würden sich durch ein großes bis sehr großes Maß von Offenheit hinsichtlich abweichender Meinungen auszeichnen. Von den Lesern waren 71 Prozent konservativer und 29 Prozent progressiver als die Zeitung. Auf der oben genannten Skala gemessen, auf der 4 die Mitte ist, kommt der Durchschnittsleser auf 3,6 (fast die Mitte) und die Zeitung auf 2,9 (links von der Mitte). 
Zur Zeit der Untersuchung (Mai 1973) schienen gut 36 Prozent der Leser eine feste bis sehr feste Bindung an die Zeitung zu haben, während 10 Prozent daran dachten, das Abonnement aufzukündigen. Die gewichtigste negative Auswirkung auf die Bindung ging offenbar zu Lasten der Unzufriedenheit über den Vertrieb der Zeitung und hing somit nicht an erster Stelle mit dem Inhalt der Zeitung zusammen. Die Unterschiede in der Gesinnung zwischen der Zeitung und den Lesern beunruhigten die Redaktion nicht, sondern ermutigten sie. "Beunruhigend würden sie nur sein" so ein Kommentar der Chefredaktion vom 14. Mai 1974 -, „wenn es die höchste Berufung einer Zeitung wäre, getreu die Auffassung des Lesers im Schnitt widerzuspiegeln, und wenn beim Nichtvorhandensein einer so leblosen Spiegelung die Leser günstigstenfalls die Zeitung grollend ertragen würden." Warum "De Tijd“ nicht interessant werden konnte für die Inserenten, zeigt das Untersuchungsergebnis mit dem Hinweis, daß 67 Prozent der Abonnenten zwei oder mehr Zeitungen lasen, während der überregionale Schnitt bei 14 Prozent liegt.

Die Probleme von "De Tijd“ als einer "von altersher katholischen Zeitung" ließen sich nicht, wie es in den fünfziger und teilweise noch in den sechziger Jahren der Fall war - in Absprache mit Zeitungen und Institutionen lösen, die in einer vergleichbaren Position waren. Die regionalen katholischen Tageszeitungen nahmen, sofern sie noch nicht eingestellt waren, eine unparteiliche, neutrale oder christlichhumanistische Färbung an und beriefen sich auf ihre Verantwortung als "one city newspaper" (einzige Zeitung am Platz) für ihre Leser verschiedener weltanschaulicher Prägung. Im Jahre $1968 \mathrm{kam}$ eine vollständige Fusion zustande zwischen den drei in einer Föderation zusammenarbeitenden Journalistenorganisationen: die "Nederlandse Vereniging van Journalisten" wurde geboren. Ein zu gleicher Zeit als Besinnungszentrum gegründetes "Katholiek Journalisten-Centrum “ kam nicht in Gang, ebensowenig wie das verwandte Institut, das evangelische "Christelijk JournalistenCentrum“. Als Papst Paul VI. am 23. November 1968 eine Ansprache über die Aufgabe der katholischen Presse und der katholischen Journalisten im Hinblick auf die Meinungsunterschiede innerhalb der Kirche hielt, berieten die Chefredakteure der niederländischen katholischen Tageszeitungen, das „Katholiek Nederlands Persbureau", die "Nieuwe Linie" und die Führung des "Katholieke Radio Omroep" (KRO = die Katholische Rundfunkgesellschaft im Rahmen des niederländischen Rundfunks) miteinander, um eine Erklärung aufzusetzen. In dieser kritisch gemeinten Erklärung stellten die Unterzeichner entschieden heraus, daß das Berufsethos des katholischen Journalisten ausdrücklich verpflichte, über neue Strömungen und Initiativen innerhalb der Kirche zu berichten, auch wenn sie von vielen Autoritätsträgern in der Kirche vorerst noch als „umstritten und zumindest nicht übereinstimmend mit den gesunden Traditionen und mir einer wirklichen Treue gegenüber den Texten des letzten Konzils und der Wahrheit des Evangeliums selbst erachtet würden", wie der Papst es ausgedrückt hatte. Dies war das letzte Mal, daß die katholischen Publizisten in den Niederlanden als Gruppe demonstrierten in dem Sinn, daß sie der kirchlichen Autorität nicht mehr untergeordnet seien. Die „acies formata“ Leos XIII. (1878-1903) und das „wie ein Mann marschieren“ des niederländischen Episkopats (1896) war nur noch Vergangenheit.

Die Vereinigung Katholiek Nederlandse Dagbladpers (KNDP) wurde im Jahre 1969 aufgelöst; das „Katholiek Nederlands Persbureau “54 wurde im Jahre 1972 geschlossen. Damit war die Demontage der nach dem Krieg wiedererrichteten Organisation vollendet. Der Einheitsgedanke hatte sich als bessere Grundlage für diese Organisationen 
und Einrichtungen erwiesen als der noch unzureichend ausgeformte Pluralitätsgedanke. Die Morgenröte der katholischen Journalistik begann mit apologetischen Streit- und Schmähschriften wie auch mit einer Zeitschrift „De Morgenster“ (Der Morgenstern, gegründet 1831) von Joachim Le Sage ten Broek und anderen. Schrieben wir im Jahre 1972 über "Die Vesper der katholischen Journalistik", so sollten wir in diesem Augenblick die Bildsprache fortsetzen können und den nun mit dem Wochenblatt "de Tijd" als Exponenten begonnenen Zeitraum als die „Komplet" der katholischen Journalistik bezeichnen. Wie lange wird es da noch dauern, ehe ein "Abendstern" einiges Licht in die Nacht bringen wird, die unwiderruflich, so scheint es uns, über das Phänomen der katholischen Journalistik in den Niederlanden hereinbrechen wird?

Wir beschließen nun diesen zweiten Beitrag und eignen beide Beiträge jenen zu, die für bisweilen wenig Lohn, aber immer mit viel Idealismus und persönlichem Einsatz für das Werk der katholischen Presse in den Niederlanden gearbeitet haben: den Journalisten, dem Personal in Verwaltung und Technik und - sofern sie nicht allzu viel Geld nur für ihre Person herausgewirtschaftet haben - den Verlegern. Wir denken hierbei insbesondere an die Menschen von "De Tijd" in der Zeit von 1968 bis 1974, als wir in bescheidenem Maße an dieser Zeitung mitarbeiten konnten. Es ist schade für die Verleger, Redaktion, Leser und alle, die an guter journalistischer Arbeit interessiert sind, daß das Experiment der letzten Jahre von "De Tijd“ nicht bis zu Ende geführt werden konnte. Die Leitlinie war es jedenfalls wert und bleibt eine Herausforderung auch für andere Zeitungen. In den Worten der Chefredaktion zusammengefaßt, lautet diese Leitlinie ja, eine offene Zeitung zu machen, die vielfältig in der Meinungsausrichtung ist, aber nicht an vorgeformten Meinungen klebt, vielmehr einen Kurs verfolgt, den sehr rechte Menschen links und sehr linke Menschen rechts nennen können.

Das Wochenblatt „de Tijd“ hat - auf einem noch sehr vorsichtig progressiven Kurs - bislang einen Erfolg für sich gebucht: die bezahlte Auflage Anfang 1975 betrug 50.000 Exemplare. Damit nimmt „de Tijd“ unter den Meinungswochenblättern in den Niederlanden den dritten Platz ein.

Anmerkungen :

1. Siehe den ersten Beitrag von J. Hemels: Katholische Presse in den Niederlanden (I): Rüdkblick anläßlich der Einstellung der Tageszeitung "De Tijd“. In: "Communicatio Socialis" 8:1975, Nr. 1, S. 1-22.

2. Vgl. zur Geschichte der niederländischen Presse während der ersten Jahre des Zweiten Weltkriegs u. a. L. de Jong: Het Koninkrijk der Nederlanden in de Tweede Wereldoorlog, Deel V: maart '41-juli '42, erster Band, 's-Gravenhage 1974, S. 282-324; siehe auch J. Hemels: Titus Brandsma und die katholische Presse der Niederlande zwischen 1935 und 1942. In: ${ }_{n}$ Communicatio Socialis ${ }^{*}$ 6:1973, Nr. 1, S. 1-25, besonders S. 24.

3. Zur Geschichte von „De Volkskrant" siehe J. Hemels: Ideaal en ideologie van een eeuw katholieke pers. Een historisch-publicisticologische analyse van een zuilelement (Unvollendetes maschinenschriftliches Manuskript, das demnächst veröffentlicht wird).

4. Vgl. für eine knappe Ubersicht J. Hemels: De vespers van de katholieke journalistiek. De ontwikkeling in Nederland gedurende een kwart eeuw. In: „De Bazuin“ 56:1972, Nr. 8, S. 3-7. 
5. Wir möchten hier J. Asberg in Bloemendaal für seine Hilfe danken; er hat uns seine eigenen Unterlagen zur Verfügung gestellt. Ein Gespräch mit C. P. M. Romme kam nicht zustande.

6. Der führende Mann der katholischen Arbeiterbewegung in den Niederlanden, A. C. de Bruin, schlug vor, das Wort "katholiek" im Kopf der neuen "Volkskrant" wegzulassen. J. M. Lücker fand, daß man dies im Hinblick auf den Episkopat und die potentiellen Leser nicht tun könne. Siehe hierzu das Interview von Jan Rogier mit J. M. Lücker in „Vrij Nederland“ vom 22. Mai 1971.

7. Vgl. auch zu diesem Abschnitt das in Anmerkung 3 genannte Manuskript von J. Hemels.

8. Im Jahre 1947 bestand die "Katholieke Nederlandsche Nieuwsblad Pers“ (KNNP) als Organisation der katholischen Herausgeber von Nachrichtenblättern, wie aus einer Meldung im Kongreßbüchlein des Kongresses „Katholieke Nederlandse Publiciteit“ (Utrecht, 31. Oktober und 1. November 1947) ersichtlich ist; die „KNNP“ und die neutrale "Nederlandsche Nieuwsblad Pers" (NNP) verfügten über ein gemeinsames Organ. Als katholische Meinungswochenblätter werden in derselben Broschüre „De Linie“ und "De Nieuwe Eeuw" genannt; mit den zehn nichtkatholischen Meinungswodhenblättern waren sie in dem 1946 gegründeten Verband „De Nederlandse Opiniepers" (Die Niederländische Meinungspresse) organisiert.

9. Siehe dazu J. Hemels: De journalistieke eierdans. Over vakopleiding en massacommunicatie, Assen 1972.

10. Diese Themen kamen zum Beispiel auf die Tagesordnung während eines Besinnungswochenendes für katholische Journalisten aus den Niederlanden und Belgien, gehalten in Tilburg im Jahre 1953; die Referate wurden publiziert in der Broschüre: Verdiepingsweekeinde voor katholieke journalisten uit Belgie en Nederland, Herbst 1953, o. O., o. J.

11. Im Jahre 1955 fand zu Valkenburg ein Kongreß statt über das Thema „De katholieke journalist in deze tijd“; die Texte der Vorträge, u. a. die von Msgr. Dr. J. M. J. A. Hanssen, Bischof-Koadjutor von Roermond, sind in einer Broschüre unter demselben Titel (o. O., o. J.) publiziert worden.

12. Zum Beispiel Erzbischof-Koadjutor B. Alfrink im Jahre 1951 und dann als Kardinal Alfrink im Jahre 1965; ferner Bischof-Koadjutor Hanssen (siehe Anmerkung 11) und Msgr. Bekkers (siehe Anmerkung 14). Siehe ferner J. Hemels: Manuskript.

13. Den Text von Rogier haben wir bis jetzt nicht beschaffen können, so daß wir nur über Berichte zu dem betreffenden Diskussionstag verfügen: siehe hierzu Hemels: Manuskript.

14. W. M. Bekkers: Kerk en krant. In: „Actio Catholica“ (Ausgabe der "Katholieke Actie in Nederland", 20:1957, Nr. 5/6, S. 182-189).

15. Siehe dazu die Berichte: „Publieke mening in de katholieke Kerk en de katholieke pers. Verslag van de op 19 februari 1957 te Utrecht gehouden discussiemiddag" (nicht gedrudkt, im Besitz von J. Hemels), "Verhouding kerkelijke overheid en pers" (Bericht des gleichnamigen Ausschusses), Utrecht, den 15. Dezember 1958 (nicht gedrudkt, ebenfalls im Besitz von J. Hemels), und L. G. A. Schlichting: De openbare mening en het concilie. In: Vriendengave Bernardus Kardinaal Alfrink aangeboden bij gelegenheid van de veertigste verjaardag van zijn priesterwijding, Utrecht/Antwerpen 1964, S. 228-238.

16. Jan Derks: Over de eer van de journalist. 50 jaren katholieke journalistenorganisatie, o. O. (1952).

17. Eeuwfeest van het herstel der bisschoppelijke hierarchie in Nederland. Toespraken, gehouden door pater M. Bogaartz S. J. en mgr. W. Nolet, bij de herdenking in Utrecht op zaterdag 9 mei 1953 door directeuren en journalisten van de katholieke pers in Nederland, Amsterdam 1953.

18. Siehe zum Entstehen des Hirtenbriefs A. F. Manning: Uit de voorgeschiedenis van het Mandement van 1954. In: "Jaarboek van het Katholiek Documentatie-Centrum“ 1971, S. 138-148. Zu den Reaktionen in der Presse auf die Passagen des Hirtenbriefs über Presse und Rundfunk siehe J. Hemels: Manuskript.

19. De katholieke pers en het vraagstuk van de katholieke eenheid. Conclusies van de werkgroep. Broschüre des „Katholieke Nederlandse Journalistenkring“ 1954. 
20. Het probleem van de katholieke journalistenopleiding. Een wachter in de nacht, von P. H-s, in "Omhoog ", 18:1951, Nr. 46, S. 1.

21. Aus Anlaß der mit dem 1. April 1959 vorgenommenen Fusion drudkte "De Tijd ${ }^{\mu}$ am 14. März einen Brief von Erzbischof B. Alfrink $a b$ mit Glüdkwünschen an die Direktionen von "De Tijd" und "De Maasbode". In diesem Brief wird auch auf die von Kardinal De Jong gewünschte Zusammenarbeit hingewiesen.

22. In der letzten Ausgabe von "Ons Noorden" vom 31. März 1964 (Nr. 17.948 des Jahrgangs 83) kam außer einer Anzahl Erinnerungsartikel auch noch die Rubrik „Katholiek Sportnieuws" vor.

23. Ende 1972 wurde H. Kouwenhoven, bis dahin Journalist, zum Pressesprecher der Niederländischen Kirchenprovinz ernannt.

24. „Nota inzake de huidige positie van de katholieke dagbladpers in ons land“ (Amsterdam, den 24. Februar 1964), hier S. 3. Vgl. auch die Broschüre "De katholieke dagbladpers in de huidige tijd. Inleidingen door: Z. E. Bern. Kardinaal Alfrink, mr. W. A. M. van der Kallen, drs. A. A. V. Tummers, prof. dr. N. de Volder, o. O., O. J. (Amsterdam-Naarden 1965).

25. Welvaart, welzijn en geluk. Een katholiek uitzicht op de Nederlandse samenleving, Band IV, S. 215-231.

26. G. W. Marsman: De katholieke dagbladpers in sociologisch perspectief. Een bijdrage tot de sociologie van de massacommunicatie, Assen 1967 und ders.: Die katholische Presse in den Niederlanden. In: Klemens Richter (Hrsg.): Katholische Presse in Europa. Ein internationaler Überblick, Osnabrück 1969, S. 71-82.

27. G. W. Marsman: a. a. O. (1967), S. 218. - Das (weltanschaulich-)pluralistische Ordnungsprinzip, das man "verzuiling (Versäulung) nennt, bestimmte die niederländische Gesellschaft bis um die Jahre 1960/1965 maßgeblich. Die Struktur des öffentlichen Lebens nach konfessionellen und weltanschaulichen Gesichtspunkten, der sich in Presse und Rundfunk, in den Fach- und Berufsorganisationen, in den Bewegungen von Jugend und Kultur sowie im Schulwesen auf allen Ebenen widerspiegelt, ist im letzten Jahrzehnt in starkem Maße auseinandergebrochen.

28. Vgl. hierzu J. Hemels: Manuskript.

29. G. W. Marsman: Massacommunicatie en ontzuiling. In: Verzuiling en ontzuiling (Broschüre „Katholieke Radio Omroep"), Hilversum 1969, S. 32-36.

30. Rooij: a. a. O. (1956), S. 262-268 und ders.: a. a. O. (1974), S. 124-139, hier S. 124.

31. M. Rooij: Verzuiling en pers. In: Pacificatie en de zuilen (J. J. Gielen u. a.), Meppel 1965, S. 52-97, hier S. 87.

32. J. Th. van den Berg und H. A. A. Molleman: Crisis in de Nederlandse politiek, Alphen aan den Rijn 1974.

33. M. Rooij: a. a. O. (1974), S. $171-177$ und J. Hemels: Entwidklung und Problematik der niederländischen Tagespresse. Ein Versuch zur Bestandsaufnahme. In: "Publizistik“, 19:1974, Nr. 2, S. 185-199.

34. M. Rooij: a. a. O. (1974), S. 176.

35. Siehe dazu Walter Goddijn: De beheerste kerk. Uitgestelde revolutie in rooms-katholiek Nederland, Amsterdam/Brüssel 1973 und J. Roes: R. K. Nederland, 1958-1973. Een encyclopedisch overzicht, Nimwegen 1974 (auch erschienen in: "Archief voor de Geschiedenis van de Katholieke Kerk in Nederland“ 16:1974, Nr. 1, S. 73-161.

36. Ausdrudk von L. van Gelder: De Tijd voltooid verleden. In: „De Bazuin" vom 30. August 1974, S. 4-5.

37. Vgl. F. J. F. M. Duynstee: Mr. L. G. A. Schlichting 1898-1968. In: Massamedia en politiek. 24 Essays ter nagedachtenis aan Prof. Mr. L. G. A. Schlichting, Utrecht 1968, S. 9-18, hier S. 12-13.

38. Der Titel dieser Ausgaben war: „De Nieuwe Dag“ mit den folgenden Untertiteln: 
"Amsterdams Dagblad“, „Nieuwe Haarlemsche Courant“, „Kennemer Dagblad“ und

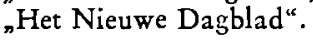

39. A. Kuiper: Een doodsstrijd die vier jaar heeft geduurd. In: „De Tijd“ vom 31. August 1974.

40. Auch behauptet von Herman van Pelt: Sportjournalistiek. In: Erich Beyer, Rob Timmer und Herman van Pelt: Grote sportencyclopedie, Tielt/Utrecht 1972, S. 114-121, hier S. 116, und J. Hemels: De sportjournalistiek in Nederland. In: "Sporta“ 25:1971, Nr. 10, S. $283-287$.

41. Eine Sonderausgabe von „De Tijd“, Ende Dezember 1971, gibt eine Ubersicht der Ereignisse und des Rettungsversuchs.

42. Interne Noten von A. J. Cuppen: De Tijd, formule en verschijningsvorm, vom 19. August 1971 und ders.: De Tijd, alternatief Dagblad, vom 23. September 1971.

43. Interview von J. Hemels und Nico Versluijs mit $H$. van Run und A. Cuppen in: „De Bazuin", 55:1972, Nr. 8, S. 6-7.

44. „De Tijd“ vom 27. November 1972 und "De Telegraaf“ vom 25. November 1972; eine zweite Polemik zwischen "De Telegraaf" ("der Feind von De Tijd") und „De Tijd": vgl. „De Tijd“ vom 29. November 1972.

45. H. van Run: Cuppen gaat en blijft. In: „De Tijd“ vom 29. Dezember 1973.

46. Zum Beispiel die Nummer vom 15. Juli 1974.

47. J. Hemels: a. a. O. 1974.

48. A. Kuiper: De Tijd heeft het weer gered. In: „De Journalist“, 25:1974, Nr. 3, S. 10-11, und zur Diskussion über die Subventionsmaßnahmen der Regierung für "De Tijd“ a. a. O., Nr. 4, S. 12-13.

49. J. Hemels: De Gordiaanse knoop van het mediabeleid. In: „Beleid en Maatschappij“, $1: 1974$, Nr. 12, S. 350-359.

50. Jan Wienema: De Tijd wordt katholiek weekblad, twaalf redakteuren gaan mee. In: De Tijd, Proeve van een geintegreerd massamediumonderzoek, deelrapporten I. A, I. B A. Kuiper (vordem Chef des Auslandsressorts von "De Tijd “) und Herausgeber ist N. Schrama (vordem Vertriebsleiter von „De $\mathrm{T}_{\mathrm{ijd}}{ }^{\alpha}$ ).

51. "De Tijd" vom 1. Juli 1974.

52. H. van Run: Tenslotte ("Vrijmoedig commentaar") und A. J. Cuppen: Was de verdwijning van „De Tijd“ onafwendbaar? In: „De Tijd“ vom 31. August 1974.

53. J. J. van Cuilenburg, J. de Jonge und G. W. Noomen: Mediumonderzoek Dagblad De Tijd, Proeve van een geintegreerd massamdiumonderzoek, deelrapporten I. A, I. B und II. Amsterdam (Uitgeverij De Tijd BV) 1974. Wir möchten an dieser Stelle N. Schrama von „De Tijd“ danken für die Aushändigung der vollständigen Berichte.

54. F. Oudejans: Geschichte und Ende des „Katholiek Nederlands Persbureau“. In: Communicatio Socialis" 6:1973, Nr. 2, S. 144-151.

\section{S U M M A R Y}

After world war II, there seemed to be no change in the catholic press of the Netherlands, compared with the situation before German occupation. Catholic professional organizations re-started, and the pre-war catholic press tried to win back its market. But a more thorough study reveals that already in the fist years after the war, there were already some indications towards the later developments. The author shows with examples how certain changes in Church and Society touched the catholic press as organ of opinion. The daily papers lost their catholic identity in 10 years time. One gained an open mentality, and the readiness for 
a change by most catholics and journalists. The catholic daily "De Tijd" tried to survin with the journalistically interesting attempt to get in about two years time, a new identit and new readers. But the growing process of polarization between the catholics in th beginning of the seventies, led to the consequence that neither the conservative nor th progressive wings could give a paper like "De Tijd" a possibility to survive.

\section{RÉSUME}

L'auteur montre, dans cet article, que la fin de la Seconde Guerre Mondiale n'a pas amené la restructuration de la presse catholique journalière aux Pays-Bas. A première vue, il semble que ces cinq années de guerre, en ce qui concerne la presse catholique, n'ont été rien de plus qu'une interruption de quelques heures dans un processus de développement de plus d'un siècle. Les organisations catholiques, dans le domaine de la presse, furent remises sur pied, et les journaux catholiques cherchèrent à reconquérir leur part d'avant-guerre sur le marché de la presse quotidienne.

Une observation plus précise permet cependant de montrer les indices de transformations intervenues au cours des années 60 , datant des quinze premières années qui suivirent la guerre. L'auteur dégage un certain nombre d'exemples. Les transformations qui commencèrent à se manifester dans l'Eglise et dans la société au début des années 60, touchèrent la presse catholique en tant que presse d'opinion. En une décennie, les quotidiens catholiques perdirent leur identité traditionelle. Mais, ils y gagnèrent une mentalité plus ouverte et une disposition plus prête à la transformation chez la plupart des catholiques et des journalistes.

Le dernier quotidien catholique suprarégional "De Tijd» essaya de survivre. Une tentative de deux bonnes années, intéressante du point de vue journalistique, avait pour but de donner à ce journal une nouvelle identité et de nouveaux lecteurs. Le processus de polarisation parmi les catholiques néerlandais, crée au début des années 70 , eut cependant pour conséquence qu'aucun des groupes combattants (conservateurs, centristes et progressistes) ne put garantir à un journal comme «De Tijd» un minimum d'existence.

\section{R E S U M E N}

En este trabajo muestra el autor que el final de la Segunda Guerra Mundial no trajo consigo reestructuración tangible alguna de la prensa diaria católica en Holanda. A primera vista parece como si cinco años de guerra no hubieran sido, en lo que a la prensa católica se refiere, más que una interrupción de pocas horas en un proceso de desarrollo que se extiende a lo largo de más de un siglo. Las organizaciónes católicas relacionadas con la prensa fueron erigidas de nuevo y los diarios católicos trataron de reconquistar la posición que disfrutaban antes de la guerra en el mercado periodístico.

Un análisis más a fondo hace posible sin embargo constatar ya en los 15 primeros años de postguerra los signos de los profundos cambios de la década de los años sesenta. El autor pone de relieve una serie de ejemplos. Los cambios que comienzan a manifestarse en la Iglesia y en la sociedad al principio de los años sesenta afectan a la prensa católica como prenso comprometida. En un decenio se pierde la identidad tradicional de los diarios católicos. Se ganó al mismo tiempo una mentalidad abierta y una predisposición a la evolución en la mayoría de católicos y periodistas.

„De Tijd“, el último diario católico suprarregional, trató de sobrevivir. Un intento, interesante desde el punto de vista periodístico, de dotar al diario de nueva identidad y nuevos lectores se prolongó durante dos años. El proceso de polarización entre los católicos holandeses, iniciado a comienzos de los años sesenta, tuvo como consecuencia que ninguno de los grupos militantes (conservadores, centristas o progresistas) pudieran garantizar un mínimo vital a un periódico como ${ }_{\nsim}$ De Tijd ${ }^{\alpha}$. 